Mexican Journal of Biotechnology 2020, 5(3):33-70

Journal homepage:www.mexjbiotechnol.com

ISSN:2448-6590

REVIEW ARTICLE

\title{
Biotechnological applications of avocado seed
}

\section{Aplicaciones biotecnológicas de la semilla de aguacate}

Jorge Arturo Mejía-Barajas

Centro de Innovación y Desarrollo Agroalimentario de Michoacán A.C., México. Antigua Carretera a Pátzcuaro, Sin número, 58341 Morelia, Michoacán, Mexico.

Corresponding author

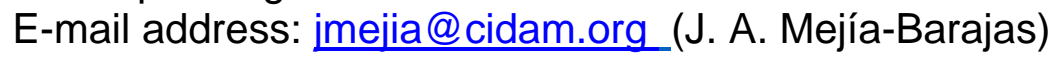

Article history:

Received: 24 March 2020 / Received in revised form: 20 May 2020 / Accepted: / 7 June 2020 / Published online: 1 July 2020.

https://doi.org/10.29267/mxib.2020.5.3.33

\begin{abstract}
Due to the various nutrients and vitamins that avocado presents, it is considered the healthiest fruit in the world. Of this fruit, only its pulp is used, generating tons of by-products in the form of shell and seed. The avocado seed (AS) represent up to $18 \%$ of the total weight of the fruit, even though it is a good source of protein and antioxidant compounds, is generally discarded, becoming a source of contamination. Therefore, a review of biotechnological applications of this byproduct of avocado is shown, where its composition, antioxidant capacity, therapeutic and antimicrobial properties are considered, as well as its use in the removal of toxic compounds and for the production of biofuels, emphasizing its toxicological risks due their anti-nutrients. The biotechnological applications and patents described in this work demonstrate the economic potential of the AS.
\end{abstract}

Keywords: Avocado seed, biotechnological applications, patents, toxicity.

\section{RESUMEN}

Debido a los diversos nutrientes y vitaminas que presenta el aguacate, este es considerado como la fruta más saludable del mundo. De esta fruta solo se utiliza su pulpa, generando toneladas de sub-productos en forma de cáscara y semilla. La semilla de aguacate (SA) que puede llegar a representar hasta el $18 \%$ del peso total de la fruta, aun cuando es una buena fuente de proteínas y compuestos 
antioxidantes, generalmente es desechada, convirtiéndose en una fuente de contaminación. Por lo anterior, se muestra una revisión de aplicaciones biotecnológicas de este sub-producto del aguacate, en donde se considera su composición, capacidad antioxidante, propiedades terapéuticas y antimicrobianas, así como su uso en la remoción de compuestos tóxicos y para la producción de biocombustibles, enfatizando sus riesgos toxicológicos debido a la presencia de anti-nutrientes. Las aplicaciones biotecnológicas y patentes que se describen en este trabajo, demuestran el potencial económico de la SA.

Palabras claves: Semilla de aguacate, aplicaciones biotecnológicas, patentes, toxicidad.

\section{INTRODUCCIÓN}

El aguacate (Persea americana) se produce en más de 60 países (Chel-Guerrero et al., 2016; FAOSTAT, 2014), entre los cuales México es el primer productor ya que genera más del $30 \%$. En México, Michoacán es el estado con la mayor producción proporcionando hasta el $80 \%$ del aguacate a nivel nacional (SIAP, 2015). El consumo de aguacate está constantemente en aumento debido a sus beneficios nutricionales, puesto que es una fuente de carbohidratos, proteínas, fibra, micronutrientes, polifenoles, grasas, aceites, vitaminas (C, E, K, B1, B2, B6, B9) y minerales (P, Na, Mg, K, Fe y Zn) (Dreher \& Davenport, 2013). Sin embargo, sus sub-productos representan hasta el $30 \%$ de la fruta, por lo que se han convertido en una fuente de contaminación ecológica (Camberos et al., 2013). Los principales sub-productos del procesamiento del aguacate son cáscara y semillas, donde este último llega ocupar del 13 al 18\% de la fruta (Ortiz et al., 2004). Aun cuando la semilla de aguacate (SA) presenta propiedades anticancerígenas, antiinflamatorias, antidiabéticas, antihipertensivas, y ha sido utilizada ampliamente en la medicina tradicional mexicana para tratar reumatismo, asma e infecciones; actualmente generalmente es desechada (López-Cobo et al., 2016; Omolara et al., 2017). Araújo et al. (2018) generaron una revisión de sub-productos del aguacate considerando tanto la cáscara como la semilla. Esta revisión muestra la historia, desarrollo y comercialización de la fruta, analizando su potencial en la industria alimenticia, cosmética y farmacéutica. Por otra parte, Bahru et al. (2019) revisaron la composición nutrimental y química, así como propiedades antioxidantes, antihipertensivas y antimicrobianas de la SA, sin considerar el potencial del mismo para la producción de energía y como absorbente de compuestos tóxicos, aplicaciones revisadas en el trabajo de Colombo \& Papetti (2019), en donde además se enfatizó la valorización de los sub-productos del aguacate para su utilización en la industria alimenticia y cosmética. El objetivo de la presente revisión fue analizar y actualizar en un solo documento, las aplicaciones biotecnológicas de la SA, además de considerar su potencial para la producción de biocombustibles, bioplástico, aceite y colorantes, e incluir una sección de estudios toxicológicos que evalúa la presencia de antinutrientes. Por último, se desarrolló una sección con aplicaciones variadas, así como la tendencia en la generación de patentes utilizando SA. La búsqueda se realizó utilizando como 
palabras claves "semilla", "aguacate", "semilla de aguacate", así como su combinación con los términos de cada subtítulo. La información fue considerada dentro de los años de 1950 a 2020, empleando los buscadores Ciencia.Science.gov, ScienceResearch.com, Microsoft Academic, Springer Link, Academia.edu, SciELo, Espacenet, google patents y FreePatentsOnline.

\section{COMPOSICIÓN Y EMPLEO EN ALIMENTOS}

Tremocoldi et al. (2018) reportaron que la SA puede ser utilizada con fines alimenticios y farmacéuticos; y Alissa et al. (2020) mediante un proceso de atomización realizaron el secado del extracto acuoso con el fin de incorporarlo en productos como sopas instantáneas y bebidas. Considerando lo anterior, a continuación, se describen los estudios sobre la determinación de la composición de la SA, así como su aplicación en la elaboración de algunos alimentos o para la obtención de ingredientes o aditivos de la industria alimenticia. Nwaogu et al. (2008) reportaron que la semilla de la fruta Persea es una buena fuente de carbohidratos, proteínas, grasas y minerales tales como calcio, fósforo, potasio y magnesio. Por otra parte, Mahawan et al. (2015) realizaron la caracterización de una harina producida a base de SA, reportando proteína cruda, fibra, grasa, carbohidratos, ceniza y humedad con valores de 7.75, 4.91, 0.71, 74.65, 2.83, y $14.05 \%$, respectivamente, sin detectar niveles de gluten. Con la harina generada se elaboraron galletas. Sin embargo, en las proporciones en las que se incorporó la harina, las galletas no presentaron características organolépticas agradables para los consumidores, lo cual se atribuyó a la presencia de taninos. Ifesan et al. (2015) evaluaron la composición nutricional y aceptabilidad de un caramelo elaborado con polvo de SA. En el análisis proximal del polvo se observó una humedad de $8.6 \%$, grasa $14.1 \%$, fibra $7.1 \%$, ceniza $2.4 \%$, proteína $23.0 \%$, y contenido de carbohidratos de $44.7 \%$. Mientras que los minerales detectados en este trabajo, así como los reportados por Egbuonu \& Opara (2017) se muestran en la Tabla 1.

\section{Table 1. Minerals reported in avocado seed flours}

Tabla 1. Minerales reportados en harinas de semilla de aguacate

\begin{tabular}{ccc}
\hline Elementos & Ifesan et al., & Egbuonu \& Opara, \\
$(\mathrm{mg} / 100 \mathrm{~g})$ & 2015 & 2017 \\
$\mathrm{~K}$ & 4.16 & 43.73 \\
$\mathrm{P}$ & 0.09 & 28.06 \\
$\mathrm{Na}$ & 1.41 & 22.11 \\
$\mathrm{Ca}$ & 0.82 & 21.12 \\
$\mathrm{Mg}$ & 0.1 & 10.23 \\
$\mathrm{Fe}$ & $\mathrm{ND}$ & 1.04 \\
$\mathrm{Zn}$ & 0.18 & 2.04 \\
\hline
\end{tabular}

ND: No determinado

Egbuonu et al. (2018) detectaron en la SA una humedad de $13.09 \%$, cenizas $3.82 \%$, fibra $2.87 \%$, proteína $2.64 \%$, y grasa $0.33 \%$, con una capacidad de 
absorción de agua de $2.70 \%$, y de aceite de $1.80 \%$. Para la semilla en polvo se ha reportado una capacidad de retención de agua y aceite de cuatro y seis veces su peso, respectivamente (Barbosa-Martín et al., 2016). La capacidad de retención de agua y aceite de la SA, así como su contribución en la textura en productos de panadería (Mugdil \& Barak, 2013) y cárnicos (Ospina et al., 2011), se ha relacionado con su alto porcentaje de fibra dietética soluble y fibra detergente neutral. Barbosa-Martín et al. (2016) realizaron la extracción de fibra de la SA utilizando $\mathrm{NaHSO}_{3}, \mathrm{NaCl}$ y trishidroximetil-aminometano, obteniendo rendimientos de entre 45 y $48 \%$. Debido a sus componentes Tugiyanti et al. (2019) evaluaron el efecto de la adición de la SA sobre la calidad de la carne de codornices (Coturnix coturnix japonica). Al alimento basal de las codornices se le adicionó la SA en concentraciones de 3 a $9 \%$. En la calidad de la carne se consideraron los niveles de proteína, grasa, colesterol, colágeno, y capacidad de retención de agua. Al analizar los resultados observaron que la adición de la SA en polvo favoreció la calidad de la carne, así como las funciones hepáticas y renales de las codornices evaluadas. Una de las áreas más estudiadas para la utilización de la SA es la obtención de almidón, ya que se ha reportado que este polisacárido puede encontrarse hasta en un 30\% en la SA (Domínguez et al., 2014; Lacerda et al., 2015). El almidón es usado ampliamente como ingrediente funcional en la industria alimentaria, debido a sus propiedades gelificantes y estabilizadoras que contribuyen en la viscosidad, textura y consistencia de productos como papel y adhesivos, así como en embalajes biodegradables. Ifesan et al. (2015) elaboraron un caramelo utilizando la semilla sub-producto del aguacate, azúcar y jengibre. La evaluación sensorial reveló que los dulces calificaron por encima del promedio en sabor y textura. Chel-Guerrero et al. (2016) evaluaron las propiedades fisicoquímicas y reológicas de almidón aislado de la semilla de Persea, reportando potenciales aplicaciones como agente espesante y gelificante, así como para ser utilizado en polímeros biodegradables para envases de alimentos, y como vehículo en sistemas farmacéuticos. Cornelia \& Christianti (2018) utilizaron el mismo polisacárido de la SA como un ingrediente para la producción de una sopa. El polisacárido aislado fue modificado mediante la adición de tripolifosfato de sodio en una concentración de 2 a 6\%. Los resultados mostraron que la sopa con el producto modificado presentó una mejor estabilidad y viscosidad que una sopa comercial; mientras que en el análisis sensorial fue más aceptable. Alves-Silva et al. (2017) caracterizaron las propiedades químicas, morfológicas y funcionales del almidón extraído de la SA, y del mismo almidón acetilado. Los gránulos del producto exhibieron una forma ovalada, mientras que la forma acetilada produjo gránulos con una forma de campana redondeada, ambos con un tamaño entre 26 y $37 \mu \mathrm{m}$. La solubilidad en agua, así como el poder de hinchamiento en agua y aceite, tanto de las formas nativas como acetiladas aumentaron al incrementar la temperatura, presentando el mayor índice de solubilidad en agua a 55 y $65^{\circ} \mathrm{C}$, respectivamente. El polisacárido acetilado mostró una disminución en su rompimiento y sinergia durante la congelación, con una mayor capacidad de absorción de aceite en comparación con el nativo. En éste trabajo se concluyó que la acetilación mejora las propiedades funcionales del almidón de la SA aumentado su potencial uso en productos alimenticios. Ginting et al. (2018) obtuvieron el almidón de la semilla mediante un método de sedimentación por gravedad por 24 
h. El producto se lavó y secó usando un horno a $70^{\circ} \mathrm{C}$ por $30 \mathrm{~min}$. El mayor rendimiento obtenido fue de $24.20 \%$ a las $24 \mathrm{~h}$, el cual presentó $16.60 \%$ de agua, $0.07 \%$ de amilosa, $73.55 \%$ de amilopectina, $0.23 \%$ de cenizas, $2.16 \%$ de proteínas, y $1.09 \%$ de grasas. En los análisis de microscopía electrónica de barrido se observaron gránulos ovalados de $20 \mu \mathrm{m}$, mientras que en el análisis de infrarrojo de transformada de Fourier se observaron grupos $\mathrm{O}-\mathrm{H}$ de alcoholes, $\mathrm{C}-\mathrm{H}$ de alcanos, y C-O de éter. Tesfaye et al. (2018) evaluaron la extracción de almidón de la SA para su aplicación en la industria textil. El polisacárido se extrajo a través de un método en húmedo, donde las condiciones óptimas fueron determinadas y optimizadas mediante experimentos diseñados con los programas experimental Box-Behnken y Statistica 13. El rendimiento de obtención fue del $64 \%$ (en peso seco) con una pureza del $90 \%$. El producto presentó funciones en la industria textil similares a una muestra comercial la cual contenía aditivos como goma arábiga y antiespumantes. Rivera-González et al. (2019) evaluaron el uso potencial de la harina de la semilla para el aislamiento de almidón y fibra. Después del procesamiento de la semilla se obtuvo un rendimiento del $27.28 \%$ del polisacárido de interés, con un bajo contenido de fibra, y un índice de absorción de agua de $2.43 \%$, solubilidad en agua de $11.22 \%$, e índice de absorción de aceite de $0.16 \%$, con una digestión in vitro considerada rápida. Con los reportes anteriores, se sugiere que la SA podría contribuir en el tránsito intestinal, retención de ácidos biliares y reducción del colesterol, mejorando la frescura, suavidad y viscosidad en productos horneados, así como la jugosidad en productos cárnicos. Además de ser una buena fuente para la obtención de almidón con potencial aplicación en alimentos.

\section{PROPIEDADES ANTIOXIDANTES}

La SA presenta hasta el $70 \%$ de los antioxidantes de todo el aguacate, así como el 64\% de los compuestos fenólicos (Wangensteen et al., 2004; Bahru et al., 2019). De acuerdo a Rodríguez-Carpena et al. (2011a) el sub-producto del aguacate puede ser empleado como nutracéutico, con propiedades antioxidantes que coadyuven en la conservación de alimentos, ya que los extractos de semilla de dos variedades de aguacate ("Hass" y "Fuerte"), son inhibidores de la oxidación de lípidos y proteínas, así como del deterioro del color de empanadas de cerdo. Wang et al. (2010) reportaron la presencia de catequina, epicatequina, procianinas, y hexámeros, en extractos de SA; mientras que Rodríguez-Carpena et al. (2011b) observaron que las cáscaras y la semilla, presentan compuestos fenólicos con un potencial antioxidante in vitro mayor que el de la pulpa, debido a la presencia de catequinas, procianidinas y ácidos hidroxicinámicos. En este último trabajo, observaron que el contenido fenólico total y el potencial antioxidante fue afectado por el solvente utilizado en la extracción de los compuestos, así como por la variedad de aguacate. Ifesan et al. (2015) evaluaron la capacidad antioxidante de una harina de SA mediante la prueba del 2.2-difenil1-picrilhidrazilo (DPPH). En sus resultados reportaron una capacidad de reducción del compuesto de 44.65\%. López-Cobo et al. (2016) concluyeron que los principales antioxidantes en la SA son polifenoles, reportando la presencia de ácido quínico, cítrico, 1-cafeoilquínico, 3-O-p-coumaroilquínico, así como de 4- 
cafeoilquínicos, glucósido de hidroxitirosol, glucósido de tirosol y glucósido de ácido vanílico y taninos. Figueroa et al. (2018) analizaron el perfil fenólico de la SA mediante cromatografía líquida de ultra alta definición. En esta investigación se identificaron 84 compuestos de los cuales los taninos, ácidos fenólicos y flavonoides fueron los más representativos. En sus resultados señalan que la semilla constituye una fuente de ingredientes bioactivos con aplicaciones en el sector alimentario, cosmético y/o farmacéutico. Segovia et al. (2016) evaluaron el efecto de la potencia del ultrasonido $(0-104 \mathrm{~W})$ y la temperatura $\left(20-60^{\circ} \mathrm{C}\right)$, en la extracción de polifenoles totales de la semilla, utilizando agua como solvente. El aumento de la temperatura y la potencia del ultrasonido dieron como resultado extractos con mayor contenido de polifenoles y capacidad antioxidante. Rosero et al. (2019) determinaron la actividad antioxidante de extractos (agua:acetona) mediante las pruebas de ABTS (Ácido 2.20-azino-bis-ácido 3-etilbenzotiazolina-6sulfónico) y DPPH, mientras que el contenido de polifenoles totales se determinó por el método Folin-Ciocalteu. De los extractos se realizó un fraccionamiento mediante una extracción en fase sólida en Amberlite XAD-7, para después someter las fracciones a una cromatografía de exclusión por tamaño en Sephadex $\mathrm{LH}-20$. Tanto los extractos como sus fracciones se analizaron por cromatografía líquida de ultra definición-acoplada a espectrometría de masas en tándem de ionización por electro aspersión (UPLC-ESI-MS/MS). Los compuestos identificados mediante esta técnica fueron ácidos orgánicos, ácidos hidroxicinámicos, catequinas, flavonoides libres y glicosilados, procianidinas diméricas y triméricas, catequinas, epicatequinas, seis derivados de quercetina, cuatro procianidinas diméricas (tres tipos $\mathrm{B}$ y un tipo A) y tres procianidinas triméricas (dos de tipo $B$ y una de tipo A). Las fracciones con más actividad antioxidante presentaron la mayor concentración de taninos condensados. Melgar et al. (2018) evaluaron las actividades antioxidantes, antimicrobianas y citotóxicas de extractos hidroetanólicos de cáscara y SA, los cuales también fueron analizados con respecto a su perfil fenólico individual, mediante cromatografía líquida de alto rendimiento con detector de matriz de diodos-espectrometría de masas en tándem (HPLC-DAD/ESI-MS). El perfil fenólico de la cáscara y semilla fue muy distinto, presentando una mayor concentración en la cáscara, principalmente de derivados de epicatequina ( $175 \mathrm{mg} / \mathrm{g}$ de extracto) y derivados clorogénicos (42.9 mg/g de extracto). Al determinar la capacidad antioxidante de sus compuestos hidrofílicos y lipofílicos, reportaron que los extractos de la semilla mostraron un potencial antioxidante de 18.1 a $276 \mu \mathrm{g} / \mathrm{mL}$, en las pruebas de especies reactivas a ácido tiobarbitúrico e inhibición de blanqueamiento de $\beta$ caroteno, respectivamente. Los valores corresponden a la concentración de la muestra que generó el $50 \%$ de la actividad antioxidante del control positivo (Trolox con valores de 10.83 y $10.25 \mu \mathrm{g} / \mathrm{mL}$, en el mismo orden de las pruebas). En cuanto a la evaluación de las propiedades antioxidantes de extractos de SA en alimentos, Segovia et al. (2014) analizaron su potencial en emulsiones de aceite en agua y productos cárnicos. Para el modelado de la extracción de polifenoles se utilizó el método de superficie de respuesta, considerando la temperatura, tiempo y concentración de solvente (etanol) como variables. En las emulsiones se analizó la oxidación primaria y concentración de peróxido, mientras que en la carne grasa se determinaron sustancias reactivas al ácido tiobarbitúrico. En las emulsiones la 
inhibición de la oxidación fue alrededor del 30\% para extractos puros, y $60 \%$ para la combinación de extractos con albúmina de huevo. Con el extracto se evitó la oxidación de carne para hamburguesa en un $90 \%$. Sin embargo, FernándezCastañeda et al. (2018) reportaron que la combinación del extracto de semilla con nitrito de sodio, el cual es utilizado en productos cárnicos para inhibir microorganismos patógenos, causó una oxidación y no inhibió el crecimiento de Staphylococcus aureus. Segovia et al. (2018) evaluaron la capacidad de inhibición de la oxidación del aceite de SA, mediante la obtención de dos extractos. Los extractos fueron obtenidos utilizando metanol puro y una mezcla de etanol-agua (50:50 v/v). En su trabajo concluyeron que los extractos de la SA son un efectivo antioxidante natural en donde sus principales compuestos antioxidantes son la catequina, epicatequina, ácido cafeoilquínico y tres compuestos de la familia de flavonoides. Dabas et al. (2019a) reportaron una capacidad de reducción de radicales de oxígeno de 2012 equivalentes Trolox/mg, así como una reducción del $33 \%$ de oxidación de lípidos, en una emulsión de aceite-agua, a una concentración de $500 \mu \mathrm{g} / \mathrm{mL}$, lo anterior por un extracto de semilla caracterizado por su intenso color naranja, el cual sugieren podría estar relacionado con su actividad antioxidante.

Además del análisis de la actividad antioxidante de la SA, tanto in vitro como en alimentos, se ha investigado tal actividad en función de la variedad de aguacate. Tremocoldi et al. (2018) evaluaron las propiedades antioxidantes de la semilla y cáscara de las variedades "Hass y Fuerte". Ambos residuos de las dos variedades de aguacate exhibieron una alta capacidad de eliminación de radicales libres (DPPH y ABTS), especies reactivas de oxígeno (peróxilo, superóxido y ácido hipocloroso) y reducción de $\mathrm{Fe}^{3+}$ a $\mathrm{Fe}^{2+}$. Ortega-Arellano et al. (2019) obtuvieron un extracto metanólico de la semilla de las variedades "Hass, Fuerte, Reed, y Colinred", y analizaron su capacidad antioxidante mediante la reducción de ABTS y FRAP. La mayor actividad antioxidante la mostró el extracto de la semilla de la variedad Reed.

Con los estudios analizados, podemos considerar la SA como una fuente de compuestos antioxidantes, con posibles aplicaciones como aditivo que reemplace los compuestos como BHA (hidroxianisol butilado) y BHT (hidroxitolueno butilado), los cuales presentan un uso restringido debido a una preocupación por los posibles efectos negativos en la salud humana (Jayaprakasha et al., 2003). Sin embargo, es necesario que en la obtención de los extractos de la SA se utilicen solventes GRAS (generalmente reconocidos como seguros) tales como etanol, agua o sus mezclas, que permitan la aplicación de los extractos en las industrias farmacéutica, cosmética y alimentaria (Kosinska et al., 2012). Además de presentar una función como conservador de alimentos, mediante sus propiedades antioxidantes, la SA podría integrarse en alimentos con propiedades nutracéuticas, ya que existe evidencias del uso de sus decocciones por las culturas azteca y maya, para el tratamiento de infecciones micóticas y parasitarias (Kunow, 2003), mientras que los herbolarios de Nigeria, utilizan el extracto acuoso de semilla de Persea americana Mill. para el manejo de la hipertensión. 


\section{PROPIEDADES TERAPÉUTICAS}

Los efectos terapéuticos reportados para la SA generados principalmente por sus extractos, se describen en la Tabla 2.

Table 2. Therapeutic effects of avocado seed

Tabla 2. Efectos terapéuticos de la semilla de aguacate

\begin{tabular}{|c|c|c|}
\hline Efecto & Descripción & Referencia \\
\hline Hemaglutinante & $\begin{array}{l}\text { Efecto en los eritrocitos de } \\
\text { humanos } A, B, A B \text { y } H\end{array}$ & $\begin{array}{l}\text { Yaakobovich \& } \\
\text { Neeman, } 1983\end{array}$ \\
\hline $\begin{array}{l}\text { Inhibición de la } \\
\text { enzima lisil oxidasa }\end{array}$ & $\begin{array}{l}\text { Inhibición in vitro de la enzima en } \\
\text { piel de rata y tibia de pollo }\end{array}$ & $\begin{array}{l}\text { Werman \& Neeman, } \\
1990\end{array}$ \\
\hline Antifibrótico & $\begin{array}{l}\text { Inhibición de la oxidasa de aorta } \\
\text { bovina }\end{array}$ & Rosenblat et al., 1995 \\
\hline $\begin{array}{l}\text { Control de } \\
\text { hipertensión }\end{array}$ & $\begin{array}{l}\text { Reducción de presión sanguínea, } \\
\text { colesterol total, niveles de } \\
\text { lipoproteínas de baja densidad y } \\
\text { triacilglicéridos }\end{array}$ & $\begin{array}{l}\text { Imafidon \& Amaechina, } \\
2010\end{array}$ \\
\hline $\begin{array}{l}\text { Control de } \\
\text { colesterol }\end{array}$ & $\begin{array}{l}\text { Disminución de colesterol en } \\
\text { ratones hipercolesterolémicos }\end{array}$ & $\begin{array}{l}\text { Pahua-Ramos et al., } \\
2012\end{array}$ \\
\hline $\begin{array}{l}\text { Tratamiento de la } \\
\text { enfermedad de } \\
\text { Alzheimer }\end{array}$ & $\begin{array}{l}\text { Inhibición de las enzimas } \\
\text { acetilcolinesterasa y butiril } \\
\text { colinesterasa }\end{array}$ & Oboh et al., 2016 \\
\hline $\begin{array}{l}\text { Control de } \\
\text { hiperglucemia e } \\
\text { hipercolesterolemia }\end{array}$ & $\begin{array}{l}\text { Reducción de glucosa y colesterol } \\
\text { en la sangre, y aumentó del } \\
\text { almacenamiento del glucógeno } \\
\text { hepático } \\
\text { Evita alteraciones histopatológicas }\end{array}$ & Uchenna et al., 2017 \\
\hline $\begin{array}{l}\text { Tratamiento en } \\
\text { cardionefrotoxicidad }\end{array}$ & $\begin{array}{l}\text { a través de mejora del sistema de } \\
\text { defensa antioxidante y supresión } \\
\text { de la acción inflamatoria }\end{array}$ & $\begin{array}{l}\text { Abdel-Moneim et al., } \\
2017\end{array}$ \\
\hline $\begin{array}{l}\text { Antiinflamatorio y } \\
\text { analgésico }\end{array}$ & $\begin{array}{l}\text { Reducción de edemas, así como de } \\
\text { contracciones abdominales } \\
\text { inducidas por ácido acético }\end{array}$ & $\begin{array}{l}\text { Kristanti et al., 2017; } \\
\text { Dabas et al., 2019b }\end{array}$ \\
\hline $\begin{array}{l}\text { Tratamiento en } \\
\text { padecimientos } \\
\text { gástricos }\end{array}$ & $\begin{array}{l}\text { Reducción del estrés oxidativo, } \\
\text { aumento de la actividad de la } \\
\text { enzima superóxido dismutasa, y } \\
\text { prevención de úlceras y cambios } \\
\text { histológicos inducidos por } \\
\text { indometacina }\end{array}$ & Athaydes et al., 2019 \\
\hline
\end{tabular}

Como se observa en la Tabla 2, las propiedades terapéuticas de la SA son diversas. Sin embargo, actualmente la actividad anticancerígena es una de las más estudiadas. Abubakar et al. (2017) reportaron que los compuestos 
triterpenoides aislados del extracto etanólico de este sub-producto, presenta una actividad citotóxica significativa contra células cancerígenas de mama (MCF-7) e hígado (HepG2), con una $\mathrm{Cl}_{50}$ de 62 y $12 \mathrm{mg} / \mathrm{mL}$, respectivamente. Alkhalf et al. (2018) compararon el contenido lipídico de un extracto cloroformo:metanol de la pulpa de aguacate, contra el de la semilla de la misma fruta. En sus resultados observaron que el extracto de la semilla presentó una mayor concentración de esteroles, así como una mayor actividad citotóxica contra las líneas celulares de cáncer de colon (HCT116) y la línea celular de cáncer de hígado (HePG2), con una $\mathrm{Cl}_{50}$ similar al del fármaco de referencia sorafinib. Para Avocatin $\mathrm{B}$, una mezcla de dos alcoholes grasos polihidroxilados, se demostró que presenta una potente actividad anticancerígena selectiva para células madre de leucemia (Ahmed et al., 2018). Dabas et al. (2019a) investigaron los posibles efectos anticancerígenos de un extracto coloreado de SA. En ensayos in vitro el extracto redujo la viabilidad de células de cáncer de mama (MCF7), pulmón (H1299), colon (HT29) y próstata (LNCaP), con una $\mathrm{Cl}_{50}$ de 19 a $132 \mathrm{~g} / \mathrm{mL}$. A nivel celular se observó que el extracto regulaba negativamente la expresión de ciclinas D1 y E2 en las células $L N C a P$, lo que se asoció con las fases del ciclo G0/G1, y la inducción de apoptosis dependiente de dosis. Estos resultados podrían ser una evidencia del potencial de la SA para ser empleado en el desarrollo agentes anticancerígenos.

Este sub-producto del aguacate, además de ser empleado debido a las propiedades terapéuticas mencionadas, se ha utilizado en la medicina tradicional mexicana para la cura de procesos infecciosos causados por hongos, bacterias y virus (Daihan et al., 2016); lo que nos demuestra un potencial empleo como antimicrobiano.

\section{PROPIEDADES ANTIMICROBIANAS E INSECTICIDAS}

La SA es usada como antimicrobiano y/o insecticida, ya sea de manera directa, en extracto o infusiones. Esta aplicación es una de las más demostradas para este sub-producto del aguacate. En la Tabla 3 se mencionan los microorganismos más importantes (por su abundancia, patogenicidad o daño en la industria alimentaria), para los cuales se ha reportado un efecto inhibitorio por la SA. 
Table 3. Microorganisms on which the avocado seed has an inhibitory effect on its growth

Tabla 3. Microorganismos sobre los cuales la semilla de aguacate presenta un efecto inhibitorio en su crecimiento

\begin{tabular}{ll}
\hline \multicolumn{1}{c}{ Microorganismos } & \multicolumn{1}{c}{ Referencia } \\
\hline Artemia salina, Aedes aegypti, Candida spp, Cryptococcus & Leite et al., 2009 \\
neoformans, y Malassezia pachydermatis & Rodríguez- \\
Bacillus cereus, S. aureus, Listeria monocytogenes, & Carpena et al., \\
Pseudomonas spp, Yarrowia lipolytica, y Aspergillus niger & 2011 \\
Leishmania donovani, L. promastigotes, S. aureus, y P. & Dharmaratne et \\
aeruginosa & al., 2012 \\
Mycobacterium tuberculosis & Lu et al., 2012 \\
Entamoeba histolytica, Giardia lamblia, Tricomoniasis & Jimenez-Arellanes \\
vaginalis, M. tuberculosis, M. fortuitum, M. avium, M. & et al., 2013 \\
smegmatis, y M. absessus & Dennis \& \\
Porphyromonas gingivalis & Wulandari, 2017 \\
Colletotrichum gloeosporioides, Monilinia fructicola, y C. & Fagundes et al., \\
gloeosporioides & 2018 \\
\hline
\end{tabular}

Falodun et al. (2014) reportaron que metabolitos de la SA mostraron una actividad antimicrobiana con $\mathrm{Cl}_{50} 13.81 \mu \mathrm{g} / \mathrm{mL}$, contra una cepa de $S$. aureus resistente a meticilina, mientras que Egbuonu et al. (2018) observaron que el extracto de SA generó una actividad antibacteriana contra $P$. mirabilis, $S$. aureus y $P$. aeruginosa, así como en contra del hongo $A$. niger, dicha actividad fue mayor que la mostrada por el antimicótico estándar, ketoconazol, concluyendo que el extracto presenta un amplio espectro de actividad antibacteriana, con una selectiva actividad antifúngica sobre todo contra $A$. niger. Jiménez-Arellanes et al. (2013) obtuvieron extractos clorofórmicos y etanólicos de la semilla de $P$. americana, para posteriormente evaluar su actividad amebicida, giardicida y tricomonicida, contra $M$. tuberculosis H37Rv, cuatro cepas de $M$. tuberculosis mono-resistentes, y dos resistentes a múltiples fármacos, así como contra cinco cepas de Mycobacterium no tuberculosas. Los extractos mostraron actividad amebicida y giardicida variada. El extracto clorofórmico inhibió el crecimiento de un aislado de $M$. tuberculosis MDR, y de tres de las cuatro cepas de referencia monorresistentes de $M$. tuberculosis. Este extracto también fue activo contra las cepas de $M$. fortuitum, $M$. avium, $M$. smegmatis y $M$. abscessus, con valores de concentración mínima inhibitoria $(\mathrm{CMI})<50 \mu \mathrm{g} / \mathrm{mL}$. Contrariamente al amplio efecto bactericida observado, el efecto fungicida solo se mostró en 2 cepas, mientras que el efecto fungistástico observado en 3 cepas ( $A$. ochraceus, $T$. viride y Penicillum ochrochloron), fue mayor en comparación con los fármacos comerciales ketoconazol y bifonazol. Báez-Magaña et al. (2019) analizaron el efecto de un extracto rico en lípidos obtenido de la SA, sobre la internalización de $S$. aureus en 
células epiteliales mamarias bovinas (bMEC). Los efectos del extracto se evaluaron mediante ensayos de turbidimetría y MTT. El extracto no mostró algún efecto antimicrobiano o citotóxico. Sin embargo, si generó una reducción de un 60 a $80 \%$, de la internalización bacteriana en bMEC. Este efecto se correlacionó con la producción de óxido nítrico y la inducción de la expresión génica de IL-10, así como con una reducción en la expresión de la citocina proinflamatoria TNF- $\alpha$. Por lo que el extracto generado podría ser empleado como una fuente de metabolitos para el control de patógenos de mastitis. Además de mostrar actividad bactericida y antifúngica sobre cepas resistentes a antibióticos, se ha reportado que la actividad de los extractos de la SA es dependiente del solvente y variedad de aguacate utilizado. Leite et al. (2009) generaron un extracto hexánico y uno metanólico de la SA, y probaron su actividad en contra de $A$. salina, $A$. aegypti, cepas de Candida spp, Cryptococcus neoformans y M. pachydermatis, mediante la técnica de microdilución. En $A$. salina los extractos de hexano y metanol mostraron una CL50 de 2.37 y $24.13 \mathrm{mg} / \mathrm{mL}$, respectivamente, mientras que en las larvas de A. aegypti, la $\mathrm{CL}_{50}$ fue de $16.7 \mathrm{mg} / \mathrm{mL}$, para el extracto hexánico, y de $8.87 \mathrm{mg} / \mathrm{mL}$, para el extracto metanolico. Se ha reportado que los extractos acuosos de la SA no generan una inhibición para Zygosaccharomyces bailii, mientras que el extracto etanolico presenta una $\mathrm{Cl}_{50}$ de $500 \mu \mathrm{g} / \mathrm{mL}$ (Raymond \& Dykes, 2010). Adesina et al. (2016) determinaron el porcentaje de mortalidad de diferentes especies de mosquitos después de $24 \mathrm{~h}$ de exposición a extractos de la semilla, observando que la mortalidad fue dependiente de la dosis. El extracto que generó mayores mortalidades en mosquitos fue el extracto de acetato de etilo, mientras que la menor actividad fue del extracto cloroformico. Cardoso et al. (2016) evaluaron la actividad antimicrobiana de dos extractos (etanolico y diclorometanico) de la SA en aislados de Streptococcus agalactiae. Los extractos fueron resuspendidos en una mezcla de etanol/agua a una concentración de $100 \mathrm{mg} / \mathrm{mL}$. La actividad antibacteriana fue evaluada usando el método de difusión en discos. El extracto etanolico presentó actividad antimicrobiana únicamente para algunos aislados de $S$. agalactiae de origen humano, mientras que el extracto con diclorometano presentó actividad antimicrobiana para todos los aislados de $S$. agalactiae evaluados. El epicarpio y la semilla de especies de aguacate "Hass, Shepard y Fuerte", se trituraron por separado y se maceraron con etanol absoluto y agua destilada, para posteriormente evaluar su actividad antimicrobiana en bacterias Gram-positivos y Gram-negativas. El extracto etanólico mostró actividad en concentraciones de 104 a $416 \mu \mathrm{g} / \mathrm{mL}$, en contra de todas las bacterias evaluadas con excepción de Escherichia coli, mientras que los extractos acuosos solo generaron una inhibición para L. monocytogenes y $S$. epidermidis. Estos estudios demuestran el amplio espectro antimicrobiano de los extractos de la semilla, así como su variabilidad en función de los diferentes solventes empleados. Lo anterior ha incrementado el interés por el aislamiento e identificación de los compuestos responsables de tales actividades. Leite et al. (2009) asociaron el efecto larvicida de fracciones de un extracto hexánico de SA con una mayor concentración de $\beta$ sitosterol y 1.2.4-trihidroxi-nonadecano. Por otro lado, las acetogeninas son compuestos bioactivos ampliamente reportadas en la semilla de Persea a las cuales se les atribuyen diferentes actividades antimicrobianas (Pacheco et al., 2017; Villarreal-Lara et al., 2019; Rodríguez-Sánchez et al., 2019). Salinas-Salazar 
et al. (2017) compararon la actividad anti-listeria de un extracto enriquecido con acetogeninas, contra la actividad de dos antimicrobianos comerciales. En sus resultados observaron que el extracto presentó 1.6 veces más de acetogeninas que la pulpa, y que la actividad de su extracto fue similar al de los antimicrobianos comerciales, por lo que concluyeron que las acetogeninas de este sub-producto del aguacate podrían ser utilizadas como un aditivo alimentario natural contra Listeria. Considerando que la efectividad de un agente antimicrobiano puede ser alterada por la matriz del alimento en donde se aplica, así como por las condiciones de almacenamiento como temperatura, humedad y niveles de oxígeno, Pacheco et al. (2017) caracterizaron la actividad, estabilidad, y efectividad anticlostridial de las acetogeninas de la SA (AcO-avocadenina y AcOavocadeno), en condiciones de procesamiento de alimentos. Los extractos además de mostrar potencial anticlostridial, presentaron resistencia al calor $\left(\leq 120^{\circ} \mathrm{C}\right)$, a alta presión hidrostática (HHP; 300-600 MPa, 3-6 min, $25^{\circ} \mathrm{C}$ ) y salinidad $(\leq 3 \% \mathrm{p} / \mathrm{v})$, con una mayor estabilidad a un $\mathrm{pH} \geq 7.0$. Villarreal-Lara et al. (2019) evaluaron la actividad antimicrobiana de acetogeninas purificadas de la SA, observando un efecto antimicrobiano mayor que los conservadores comerciales Nisaplin $\AA$ y Mirenat ${ }^{\circledR}$. El extracto de la SA con un alto porcentaje de acetogeninas y registrado como Avosafe $\AA$, generó una inhibición del crecimiento de bacterias Gram (+) de 2 a 4 veces más que los conservadores comerciales, e inhibió el crecimiento de $L$. monocytogenes al ser adicionado a un alimento que contenía carne. Rodríguez-Sánchez et al. (2019) identificaron y cuantificaron las acetogeninas presentes en el extracto de la $S A$, Avosafe $\AA$, para posteriormente evaluar su potencial toxicidad mediante pruebas de mutación inversa en bacterias y toxicidad oral aguda en ratas. En el extracto se identificaron dos acetogeninas (AcO-avocadyne-(0) y AcO-avocadiene B-(3)), así como otros siete compuestos. En sus resultados no se observó actividad mutagénica o toxicidad a la concentración máxima probada (>2000 mg/Kg). De acuerdo a estos estudios podemos sugerir que de los compuestos presentes en la SA, las acetogeninas presentan el mayor avance en sus estudios para ser empleadas comercialmente.

Además de presentar diversos compuestos con propiedades antimicrobianas, la SA tiene la capacidad de remover elementos tóxicos de fuentes contaminadas, como se muestra a continuación.

\section{REMOCIÓN DE COMPUESTOS TÓXICOS}

La industria textil es una de las mayores fuentes de contaminación de aguas a causa de la gran cantidad de colorantes que emplea en sus productos (Kant, 2012). Estudios sobre la capacidad de absorción de colorantes y compuestos tóxicos muestran que el polvo de la SA podría utilizarse de manera eficiente para el tratamiento de aguas residuales, así como para la eliminación de diferentes colorantes. Devi, (2010) generó un carbón empleando esta semilla y determinó su eficiencia en la reducción de la demanda química de oxígeno (DQO) y demanda bioquímica de oxígeno (DBO), en aguas residuales del procesamiento de café. El carbón activado fue generado mediante la exposición de la semilla a $\mathrm{H}_{2} \mathrm{SO}_{4}$, y temperaturas de hasta $600^{\circ} \mathrm{C}$. En condiciones óptimas de funcionamiento del 
carbón producido, la reducción porcentual de DQO y DBO, fue de 98.28 y 99.19\%, respectivamente, mientras que un carbón activado comercial presentó valores de 99.12 y $99.45 \%$, en igual orden. El-Sayed \& El-Sayed, (2014) evaluaron las características de carbón activado generado a partir sub-productos de Persea, y compararon su capacidad de absorción con respecto al carbón producido con mazorcas de maíz y granos de ciruela, observando que el producto del aguacate presentó mejores características de absorción. Bhaumik et al. (2014) estudiaron la factibilidad de emplear la semilla carbonizada con $\mathrm{H}_{2} \mathrm{SO}_{4}$, como un absorbente de bajo costo para la eliminación de $\mathrm{Cr}(\mathrm{VI})$ de aguas residuales. El absorbente retuvo la capacidad original de adsorción de $\mathrm{Cr}$ (VI) hasta en tres ciclos consecutivos de absorción-desorción. El mecanismo de absorción propuesto fue mediante una atracción electrostática del $\mathrm{Cr}(\mathrm{VI})$ al absorbente y su posterior reducción a $\mathrm{Cr}$ (III). $\mathrm{La}$ actividad absorbente del polvo generado con el $\mathrm{H}_{2} \mathrm{SO}_{4}$ fue dependiente de la temperatura y $\mathrm{pH}$, incrementando tal actividad con la temperatura y un $\mathrm{pH}$ de 2 . Dávila-Jimenez et al. (2015) desarrollaron un compuesto de óxido de titanio utilizando como material absorbente SA carbonizada. El compuesto desarrollado fue utilizado para la degradación fotocatalítica del colorante antraquinónico, ácido verde 25. El producto de la fotodegradación no mostró toxicidad ya que permitió el crecimiento de la bacteria Azospirillum brasilense. El cristal violeta es otro colorante ampliamente utilizado en productos como papel, fertilizantes, detergentes, anticongelantes, tintas para imprimir y bolígrafos (Pavan et al., 2014), por lo anterior, es que actualmente se utilizan diferentes métodos para eliminar éste compuesto del agua (Kaur et al., 2015; Ren et al., 2015). Bazzo et al. (2015) llevaron a cabo la eliminación de cristal violeta de soluciones acuosas utilizando $\mathrm{SA}$ en polvo. En el estudio se evaluaron los efectos de condiciones tales como el $\mathrm{pH}$ de la solución, la concentración inicial de colorante, tiempo de contacto y temperatura. En sus resultados reportaron que la absorción del colorante mediante el polvo generado es un proceso exotérmico, con una eliminación máxima de 95.9 $\mathrm{mg} / \mathrm{g}$, por cada $100 \mathrm{mg}$ de polvo; lo anterior a un $\mathrm{pH} 7$ y $55^{\circ} \mathrm{C}$. Elango et al. (2015) generaron nanopartículas de óxido de estaño, mediante un método verde en donde fue calentado un extracto metanolico de Persea y una solución de cloruro de estaño. Las nanopartículas presentaron un diámetro de alrededor de $4 \mathrm{~nm}$ y la capacidad de degradar el compuesto rojo de fenol; colorante que causa irritación en ojos y piel, con potencial para causar la muerte. Zhu et al. (2016) elaboraron carbón activado a partir de SA y ácido metanosulfónico, el cual fue caracterizado y evaluado como un absorbente de amonio. Las variables consideradas en el estudio fue efecto de $\mathrm{pH}$, concentración de absorbente y de amonio, así como tiempo de contacto con el compuesto a eliminar. La capacidad de absorción teórica máxima fue de $5.4 \mathrm{mg} / \mathrm{g}$ a $25^{\circ} \mathrm{C}$. Posteriormente, Zhu et al. (2018) nuevamente elaboraron carbón activado utilizando ácido metanosulfónico, con el objetivo de eliminar de p-cresol y p-cresol combinado con amonio. La presencia de amonio no afectó la absorción de p-cresol, pero la presencia de p-cresol si influyó negativamente en la absorción de amonio. Leite et al. (2018) mediante un proceso de pirólisis generaron carbón activado. La temperatura y el tiempo de pirólisis afectaron de manera importante el volumen de poro y el valor de los grupos funcionales del carbón generado, el cual exhibió áreas de superficie específicas para 25 compuestos orgánicos emergentes, 10 productos farmacéuticos y 15 
compuestos fenólicos, además de presentar superficies hidrofílicas y grupos predominantemente ácidos. El carbón activado con mayor capacidad absorbente fue el preparado a la mayor temperatura de pirólisis $\left(700^{\circ} \mathrm{C}\right)$.

En base a los estudios sobre la capacidad absorbente de la SA, ya sea en forma nativa o tratado mediante ácidos o procesos de calentamiento, es posible concluir que este se puede emplear como materia prima para producir un carbón activado, con una gran superficie de adsorción de contaminantes orgánicos actuales y/o emergentes.

Durante el proceso de carbonización la semilla es sometida a procesos de combustión en donde se libera energía, por lo que a continuación se muestran estudios en donde se ha evaluado su producción de energía en forma de biocombustibles.

\section{PRODUCCIÓN DE BIOCOMBUSTIBLES}

Debido a su valor calorífico (16.7 MJ/Kg), alto contenido de polisacáridos $(75 \%)$ y bajo contenido de ceniza (2.2\%), la SA se considera como una biomasa residual adecuada para la producción de biodiesel y bioetanol (Sánchez et al., 2017). Deepalakshmi et al. (2014) reportaron un rendimiento de $94.40 \%$ en la producción de biodiesel a partir de este sub-producto. En el proceso se utilizó $\mathrm{KOH}$ como catalizador, además de metanol. El proceso se llevó a cabo a $65^{\circ} \mathrm{C}$, y $600 \mathrm{rpm}$, con un tiempo de reacción de $50 \mathrm{~min}$, utilizando como co-solvente tetrahidrofurano. El biodiesel obtenido del escalamiento del proceso presentó una alta estabilidad a la oxidación. Durak \& Aysu, (2015) evaluaron la pirólisis de la SA a temperaturas entre 400 y $600^{\circ} \mathrm{C}$, con el objetivo de obtener productos sólidos (biocarburantes) y líquidos (bioaceite). La pirólisis lenta de la semilla se realizó en un reactor tubular de lecho fijo con $\mathrm{KOH}$ y $\mathrm{Al}_{2} \mathrm{O}_{3}$. La cantidad de bio-carbón, gas, y bioaceite, así como la composición de éste último, fueron determinados mediante cromatografía de gases acoplado a masas y análisis de infrarrojo de transformada de Fourier. El mayor rendimiento del líquido obtenido fue de $37.5 \%$, usando $\mathrm{KOH}$ al $10 \%$, a $600^{\circ} \mathrm{C}$, con una velocidad de calentamiento de $50^{\circ} \mathrm{C}$ por min. Sánchez et al. (2017) realizaron la valorización energética de la semilla mediante su transformación termoquímica en un reactor rotativo. Las temperaturas utilizadas fueron de entre 150 y $900^{\circ} \mathrm{C}$. La temperatura óptima de la torrefacción fue a $304^{\circ} \mathrm{C}$, obteniendo un rendimiento de sólidos de $50 \%$ en peso, y un rendimiento energético de $76,7 \%$. La carbonización a temperaturas entre 500 y $900^{\circ} \mathrm{C}$ produjo entre 20 y $25 \%$ de carbón, una fracción líquida del 53 al $56 \%$, con un contenido de agua entre 70 y $75 \%$, y valores de calentamiento de $3 \mathrm{MJ} / \mathrm{Kg}$. La proporción de la biomasa original transformada en aceites orgánicos, que va de 12 a $16 \%$, fue similar a los reportados para otros residuos agroindustriales. Perea-Moreno et al. (2016) evaluaron la idoneidad de la SA como biocombustible sólido para calefacción doméstico e industrial. En el estudio fue determinada la humedad, composición elemental, cenizas, contenido de aceite, y valores de calentamiento. Los resultados obtenidos fueron comparados con los mostrados para otras fuentes de energía, como la semilla de oliva y la cáscara de almendra. La SA mostró una mayor proporción de humedad y cenizas, por lo que su empleo como combustible 
demanda un mayor mantenimiento de la caldera utilizada, así como un método de secado previo a su combustión. Por otra parte, los niveles de cloro fueron casi indetectables, lo que genera una menor corrosión en los equipos utilizados. Uno de los resultados más importantes fue el valor calorífico de $19.15 \mathrm{MJ} / \mathrm{Kg}$, que fue superior al reportado para otros biocombustibles como es la semilla de olivo (17.884 MJ/Kg), cáscaras de almendras $(18.275 \mathrm{MJ} / \mathrm{Kg}$ ) y pellets de madera de olivo (18.720 MJ/Kg) (Álvarez et al., 2015). El almidón presente en la semilla se puede emplear para la producción de bioetanol mediante pretratamientos físicos, químicos, biológicos o fisicoquímicos, que permitan la liberación de la glucosa para su posterior fermentación a bioetanol (Aditiya et al., 2016; Bahry et al., 2017). Woldu \& Tsigie, (2015) determinaron que la condición óptima para producir azúcares reductores es mediante una hidrólisis ácida con $\mathrm{H}_{2} \mathrm{SO}_{4}$ al $2 \%$, durante 24 $\mathrm{h}$, a $30^{\circ} \mathrm{C}$. Abebe et al. (2015) emplearon SA en polvo como materia prima para la producción de bioetanol. El mayor rendimiento de $6.36 \mathrm{~g} / \mathrm{v}$ de etanol se obtuvo a los tres días de fermentación, a un pH de 5.5 y $30^{\circ} \mathrm{C}$.

Kowalski et al. (2017) realizaron estudios sobre hidrólisis enzimática de SA para producir etanol de segunda generación. Los resultados mostraron que esta biomasa es una buena materia prima para la producción de bioetanol, ya que se estimó una producción de $44 \mathrm{~L}$ de etanol por tonelada de semilla. La producción de biocombustibles a partir de este sub-producto del aguacate, además de poder llevarse a cabo mediante la fermentación del almidón, puede ser realizada utilizando el aceite obtenido del mismo. Rachimoellah et al. (2010) evaluaron la producción de biodiesel a partir de aceite de la semilla de Persea gratissima. Dentro de su análisis se consideró el efecto de la relación molar del aceite y metanol, temperatura de reacción y método de lavado, lo anterior con el objetivo de obtener el mayor contenido de éster metílico. El proceso de transesterificación se realizó durante $60 \mathrm{~min}$, utilizando como catalizador $\mathrm{NaOH}$ al $1 \%$. El aceite obtenido mostró una concentración menor a $2 \%$ de ácidos grasos libres, por lo que el proceso de transesterificación puede llevarse sin la conversión de estos ácidos en ésteres. El biodiesel obtenido presentó impurezas como glicerina y metanol, por lo que fue lavado considerando diferentes métodos. El mayor rendimiento se generó con una relación molar de 1:6 (alcohol:aceite) a $60^{\circ} \mathrm{C}$, lavando el producto en seco. Hiwot, (2017) utilizó SA de la región de Wenago y Dila (Etiopía, África), como fuente de aceite. El aceite se extrajo mediante el método soxhlet utilizando hexano como solvente. El contenido de aceite y su conversión a biodiésel fue del $27,6 \%$ y $95,2 \%$, para la semilla de Wenago, y $27.2 \%$ y $94.86 \%$, para la semilla de la región de Dila. En el biodisel obtenido se identificó la presencia de palmitato de metilo, linoleato de metilo, oleato de metilo y estearato de metilo. Dagde, (2019) llevo a cabo la extracción de aceite de la SA en condiciones similares a las realizadas por Hiwot, (2017). El aceite se transesterificó con metanol en una proporción 5:1 aceite/metanol. Como catalizador fue utilizado $\mathrm{KOH}$. El rendimiento de biodiesel obtenido fue del $78 \%$, el cual presentó una densidad relativa de 0.86 $\mathrm{g} / \mathrm{mL}$, número de octano de 62.20 y viscosidad cinemática de 3.94 cst, con propiedades físico-químicas similares a las del biodiesel estándar; de este trabajo se concluye que el biodiesel generado con el aceite de la SA podría emplearse como un recurso energético alternativo en motores diésel. 
Aun cuando los reportes mostrados indican que la producción de biocombustibles a partir de la SA es viable de acuerdo a los rendimientos obtenidos, así como por las características del aceite producido; es necesario evaluar su viabilidad comercial comparando con los biocombustibles actuales.

\section{BIOMASA PARA LA OBTENCIÓN DE ACEITE}

Como se describió anteriormente, la SA es empleada para la obtención de aceite el cual contiene antioxidantes y compuestos fenólicos (Soong \& Barlow, 2004). Sin embargo, tal aceite también puede ser esterificado para la producción de biodiesel. Roger (1999) reportó que este aceite se puede aplicar en el control de la obesidad; mientras que Werman et al. (1991) estudiaron su efecto sobre el metabolismo del colágeno de la piel de ratas. Para lo anterior, aceites obtenidos de diferentes partes del aguacate fueron integrados en la dieta de las ratas en un $10 \%(\mathrm{p} / \mathrm{p})$. Las ratas que fueron alimentadas con aceite de aguacate sin refinar, así como con aceite de SA, mostraron aumentos significativos en el contenido de colágeno soluble en piel. Tal aumento se sugiere fue debido a la inhibición de la enzima lisil oxidasa, ya que el efecto solo fue observado en fracciones con una alta concentración de lípidos. Pushkar et al. (2001) caracterizaron los aceites de la pulpa y SA, detectando mediante cromatografía de gases la presencia de 22 y 27 ácidos grasos, respectivamente. El ácido palmítico fue el principal ácido presente en concentraciones de $21.3 \%$ en pulpa y $20.8 \%$ en semilla. La principal diferencia entre estos aceites fue en el contenido de ácidos grasos mono-insaturados y poliinsaturados. En la Tabla 4 se muestra la comparación de algunas propiedades del aceite obtenido de pulpa y de la SA.

\section{Table 4. Physicochemical properties of avocado pulp and seed oil}

\section{Tabla 4. Propiedades fisicoquímicas del aceite de pulpa y semilla de aguacate}

\begin{tabular}{lcc}
\hline \multicolumn{1}{c}{ Parámetros } & Pulpa & Semilla \\
\hline Contenido de lípidos $(\%)$ & 15.39 & 1.87 \\
Densidad específica $(\mathrm{g} / \mathrm{mL})$ & 0.92 & 0.93 \\
Índice de peróxidos $(\mathrm{mEq} / \mathrm{Kg})$ & 1.4 & 1.37 \\
Índice de acidez $(\%)$ & 2.45 & 4.12 \\
Valor de yodo $(\mathrm{g} / 100 \mathrm{~g})$ & 77.6 & 69.4 \\
Valor de saponificación $(\mathrm{mg} / \mathrm{g})$ & 178.3 & 231.6 \\
\hline
\end{tabular}

Dreher \& Davenport (2013) analizaron las propiedades fisicoquímicas de aceite extraído de la SA, así como la presencia de antioxidantes en el mismo. Los parámetros fisicoquímicos determinados fueron índice de acidez $(4.51 \mathrm{mg} \mathrm{KOH} / \mathrm{g})$ índice de peróxido $(2.40 \mathrm{mg} \mathrm{O} / \mathrm{Kg})$ e índice de éster $(31.26 \mathrm{mg} \mathrm{KOH} / \mathrm{g})$. En cuanto al contenido de compuestos antioxidantes el aceite presentó un contenido de flavonoides (80 mg QE/g), 10 veces mayor que el de compuestos fenólicos (8,27 
mg GAE/g). Gidigbi et al. (2019) evaluaron la viabilidad industrial de la extracción de aceite de la semilla de Persea. El rendimiento del proceso de extracción fue de $18.10 \%$. Al aceite obtenido se le determinó su índice de refracción (1.45), valor de yodo $(43.86 \mathrm{~g} / 100 \mathrm{~g})$, índice de acidez $(2.47 \mathrm{mg} \mathrm{KOH} / \mathrm{g}$ ), índice de peróxido (26 $\mathrm{mg} \mathrm{O} / \mathrm{Kg}$ ) y valor de saponificación (228 $\mathrm{mg}$ de $\mathrm{KOH} / \mathrm{g}$ ). De los ácidos grasos presentes en el aceite obtenido el ácido oleico fue el de mayor proporción (67.80\%). Bereded, (2019), de la semilla extrajo aceite y una fracción rica en taninos, los cuales se emplearon para la preparación de un agente retenedor de lubricantes y recurtidor. Mediante un análisis de FT-IR se identificó la presencia de un doble enlace en el aceite. Tal propiedad hace factible su modificación química para la producción de lubricantes, plastificantes y estabilizadores, contribuyendo al empleo de la semilla para la producción de bioplásticos.

\section{BIOMASA PARA LA PRODUCCIÓN DE BIOPLÁSTICO}

Debido al corto tiempo de uso del plástico convencional, así como a su gran acumulación, se considera que su producción no es sostenible (Muneer, 2014). Lo anterior, aunado a la creciente preocupación ambiental ha impulsado el desarrollo de industrias de materiales biodegradables. El bioplástico es un material orgánico renovable, generado a partir de polisacáridos generalmente de papa, semillas de jaca, sagú, y/o maíz (Lubis et al., 2014). Ginting et al. (2018) investigaron el efecto de la temperatura de gelatinización y la adición de quitosano sobre las propiedades físicoquímicas de un bioplástico generado con almidón de la SA. La variación en la composición fue de 7:3, 8:2 y 9:1, almidón de SA: quitosano. Las temperaturas evaluadas variaron de 80 a $90^{\circ} \mathrm{C}$. En sus resultados reportaron que una temperatura de $90^{\circ} \mathrm{C}$, en una relación almidón de SA: quitosano, 7:3, fueron las mejores condiciones para la producción del bioplástico. El producto presentó una resistencia a la tracción de $5.09 \mathrm{MPa}$, y alargamiento a la rotura de $14.01 \%$. Lubis et al. (2018) estudiaron el efecto de la adición de glicerol y celulosa microcristalina derivada de fibras de palma de azúcar, sobre las propiedades mecánicas de bioplástico generado. El bioplástico se fabricó mediante la técnica de fundición en solución, para lo cual las fibras de palma de azúcar se sometieron a un tratamiento con álcali, blanqueamiento e hidrólisis con $\mathrm{HCl}$. Como ingrediente plastificante se empleó glicerol. Las propiedades mecánicas del bioplástico se determinaron mediante la evaluación de la resistencia a la tracción y el alargamiento en el análisis de rotura. Los mejores resultados se obtuvieron utilizando una relación 7:3, almidón de SA: celulosa microcristalina, con la adición de glicerol en una concentración 0.2 volumen/peso.

\section{PRODUCCIÓN DE COLORANTES}

Cuando la SA se encuentra fresca presenta un intenso color naranja que se ha vinculado con la presencia de carotenoides, ya que $\mathrm{Ge}$ et al. (2019) identificaron 11 genes relacionados con la biosíntesis de estos compuestos, los cuales desarrollan colores como el naranja. Dabas et al. (2011) reportaron que mientras el color de la SA es dependiente de la actividad de la enzima polifenol oxidasa y del $\mathrm{pH}$ de la solución; un tratamiento térmico, así como la adición de tropolona, impiden el desarrollo del mismo. De acuerdo a este último trabajo, la formación del 
color da lugar a una disminución en la concentración de polifenoles, lo que indica la utilización de tales compuestos para su formación. Ariestya et al. (2015) evaluaron la extracción del colorante de la SA mediante ultrasonido. Como solvente se utilizó metanol en diferentes relaciones con temperaturas de 30 a $70^{\circ} \mathrm{C}$. El análisis de la intensidad de color se realizó utilizando un espectrofotómetro de UV-Vis, mientras que sus compuestos fueron identificados mediante cromatografía de gases acoplado a masas. El máximo rendimiento de obtención del colorante fue de $22.6 \%$ a una temperatura de $70^{\circ} \mathrm{C}$. En sus resultados identificaron al furfural como el responsable del color naranja. Por otro lado, Hatzakis et al. (2019) mediante cromatografía en columna de alta eficiencia identificaron el compuesto perseorangin como el principal compuesto responsable del color amarillo-naranja. Como se menciono en apartados anteriores, Dabas et al. (2019b), determinaron que el extracto metanólico coloreado de la SA, presenta actividad antiinflamatoria, antioxidante y anticancerígena.

Con los reportes anteriores, se sugiere que la SA es una fuente potencial de nuevos colorantes naturales con posibles propiedades antioxidantes para uso en alimentos.

\section{OTRAS APLICACIONES}

Además de los potenciales usos comerciales descritos, en las que existe por lo menos tres reportes que fundamentan su potencial, en la literatura se encuentran otras aplicaciones que se describen a continuación.

La SA se ha utilizado en la industria cosmética para reducir la formación de erupciones cutáneas y control de la caspa (Morton \& Dowling, 1987), mientras que los alcoholes grasos polihidroxilados extraídos de la semilla con solventes orgánicos, tienen una función fotoprotectora de células de la piel (Rosenblat et al., 2011). Bangerth, (2008), reportó la posibilidad de que la SA pudiera producir y excretar inhibidores de la maduración de la pulpa de aguacate, mientras que Hershkovitz et al. (2010) evaluaron la contribución de la semilla en la maduración de la pulpa de aguacate, enfatizando su función en la biosíntesis de etileno y vías de respuesta a este compuesto. En sus resultados observaron que, tanto a temperatura ambiente como en refrigeración, la maduración fue mayor en la fruta sin la semilla. En cuanto a vías de repuesta, determinaron diferencias significativas en los niveles de ARNm del gen PaCTR1; gen que se activa en respuesta a niveles endógenos o exógenos de etileno. La mayor tasa de maduración de la pulpa de aguacate fue acompañada con un aumento en los niveles de los genes PaACO y PaACS1, los cuales están involucrados en la síntesis de etileno. El fruto sin la semilla mostró una respuesta temprana a etileno exógeno, así como un mayor ablandamiento y tasa de respiración, en comparación de la fruta con la semilla. Por lo tanto, se concluyó que la SA participa en la regulación de la respuesta de etileno, retrasando el proceso de maduración cuando se encuentra presente en la fruta.

La composta es ampliamente utilizada para mejorar la materia orgánica y nutrientes del suelo, o para el control de hierbas y retención de agua. Parámetros 
como la relación de carbono:nitrógeno, $\mathrm{pH}$, contenido de materia orgánica, salinidad, nitrógeno total, fósforo total, fitotoxicidad, boro, cloro, sodio, tamaño de partícula, así como concentración de metales y patógenos, son variables que impactan en la calidad de un sustrato para ser empleado como composta (Bronick \& Lal, 2005). González-Fernández et al. (2015) evaluaron la viabilidad del cocompostaje de residuos de producción de guacamole (semilla y cáscara) y residuos de poda de jardín. Los resultados de las pruebas no mostraron fitotoxicidad, ya que las plantas sembradas en los sustratos con la composta generada, exhibieron un mayor crecimiento que las plantas control. De acuerdo a este trabajo, el compostaje elaborado utilizando SA, cumplió con normas europeos para ser empleada como composta comercial. Debido a que la capacidad del uso de un sustrato como composta depende de variables específicas de cada cultivo, la aplicación en diferentes cultivos debería ser evaluada mediante el análisis TMECC (Test Methods for the Examination of Composting and Compost), método utilizado por la industria de la composta para caracterizar los productos compostables (Leege, 1998).

Tzintzun-Camacho et al. (2016) elaboraron un medio de cultivo microbiológico a partir de un hidrolizado de la SA. La funcionalidad del medio se determinó mediante el crecimiento de E. coli en un biorreactor con agitación. Como resultado se observó una producción de biomasa 2.5 veces mayor, al obtenido con el medio Luria-Bertani. Por lo que en éste trabajo concluyen que este sub-producto del aguacate constituye un material útil para el crecimiento de $E$. coli, y otros microorganismos de interés biotecnológico. Sin embargo, se recomienda considerar el amplio espectro antimicrobiano que se describió previamente en este trabajo, ya que uno de los microorganismos que muestra resistencia al efecto inhibitorio de la semilla, es justamente E. coli (Cardoso et al., 2016).

Gustil et al. (2019) evaluaron la actividad anticorrosiva del extracto metanólico de la SA, aplicándolo en acero que posteriormente se sometió a una solución de $\mathrm{H}_{2} \mathrm{SO}_{4} 0.75 \mathrm{M}$. La inhibición de la corrosión se observó a una concentración de 10 $\mathrm{g} / \mathrm{L}$, evitando hasta el $74.56 \%$ de pérdida de peso y $68.38 \%$ de polarización potenciométrica. Mediante imágenes de análisis de microscopia electrónica de escáner se observó que el extracto formó una capa delgada sobre la superficie del acero, la cual sugieren fue por la interacción de grupos $\mathrm{OH}$ y $\mathrm{CN}$.

Palmerín-Carreño et al. (2019) evaluaron la producción de lactato mediante la cepa lactogénica de $E$. coli JU15, usando como medio de cultivo un hidrolizado de SA. El crecimiento microbiano se llevó a cabo en un biorreactor de $3 \mathrm{~L}$, el cual contaba con agitación controlada. La capacidad hidrolítica de la cepa utilizada fue de $0.52 \mathrm{~g} / \mathrm{L}$ por $\mathrm{h}$, con una producción de ácido láctico de $37.8 \mathrm{~g} / \mathrm{L}$. El reporte anterior demuestra que los nutrientes presentes en la semilla pueden ser aprovechados para el crecimiento de diferentes microorganismos, que generen metabolitos de interés industrial, como el ácido láctico, compuesto que por sus propiedades está considerado dentro de las 10 moléculas de mayor potencial de producción en biorefinerias. 


\section{PRESENCIA DE ANTI-NUTRIENTES Y TOXICIDAD}

La SA tanto en la industria alimentaria como en las diversas aplicaciones mostradas, está en contacto directo y/o indirecto para los consumidores o usuarios, por lo que considerar su grado de toxicidad es imprescindible. Esta toxicidad podría ser debido a los compuestos presentes de forma natural o por los generados durante su transformación. En las secciones anteriores se muestran trabajos en donde se reporta la identificación de diferentes fitoquímicos de la SA; estos fitoquímicos en función de su concentración pueden generar un efecto favorable para el consumidor o actuar como antinutrientes (Kunatsa et al., 2020). Los antinutrientes son sustancias de origen natural o sintético que se asocian con compuestos e interfieren en la absorción de nutrientes, reduciendo su ingesta, digestión y utilización, además de que pueden generar otros efectos adversos como náuseas, hinchazón, dolores de cabeza, y erupciones cutáneas (Gemede \& Ratta, 2014; Essack et al., 2017). Los antinutrientes se pueden acumular en hojas, raíces y frutos de ciertas variedades de plantas, pero sus mayores concentraciones se encuentran en la semilla (Popova \& Mihaylova, 2019), de ahí la importancia de considerar su presencia en los productos de la SA. Los principales antinutrientes que se encuentran en los alimentos de origen vegetal son oxalatos, fitatos, taninos, lectinas, y saponinas. El oxalato es un compuesto que evita que el calcio sea absorbido por el cuerpo (Jiru \& Urga, 1995), mientras que los taninos al ser consumidos en exceso, pueden inhibir algunas enzimas que participan en la absorción de nutrientes. Por otra parte, el consumo de fitatos puede conducir a una menor absorción de minerales, y las lectinas causan diversas reacciones adversas en el cuerpo (Gupta et al., 2015). Otro antinutriente relevante son las saponinas, las cuales se han relacionado con daño celular, inhibición enzimática y distorsión de la función de la glándula tiroidea (Fan et al., 2013). Henry et al. (2015) reportaron que las concentraciones de taninos detectados en la semilla fresca pueden generar una toxicidad para el consumidor, por lo que es necesario realizar un tratamiento que reduzca y/o elimine estos compuestos, previo a su consumo. En la Tabla 5 se muestran las concentraciones de compuestos reportados para la SA, los cuales en función de su concentración pueden actuar como antinutrientes. 
Table 5. Compounds detected in avocado seeds with possible antinutrient activity

Tabla 5. Compuestos detectados en la semilla de aguacate con posible actividad de antinutrientes

\begin{tabular}{lccc}
\hline Compuesto $(\mathrm{mg} / 100 \mathrm{~g})$ & $\begin{array}{c}\text { Talabi et al., } \\
2016\end{array}$ & $\begin{array}{c}\text { Egbuonu et al., } \\
2018\end{array}$ & $\begin{array}{c}\text { Ejiofor } \text { et al., } \\
2018\end{array}$ \\
\hline Taninos & 11.29 & 1.14 & $\mathrm{ND}$ \\
Oxalato & 4.07 & $\mathrm{ND}$ & 14.98 \\
Ácido fítico & 12.87 & $\mathrm{ND}$ & 3.18 \\
Saponinas & $\mathrm{ND}$ & 8.10 & $\mathrm{ND}$ \\
Alcaloides & $\mathrm{ND}$ & 2.14 & $\mathrm{ND}$ \\
Flavonoides & $\mathrm{ND}$ & 1.81 & $\mathrm{ND}$ \\
Glucósidos cianogénicos & $\mathrm{ND}$ & 1.02 & $\mathrm{ND}$ \\
Fenoles & $\mathrm{ND}$ & 0.29 & $\mathrm{ND}$ \\
\hline
\end{tabular}

ND: No determinado

Como se observa en la Tabla 5, la concentración de los antinutrientes detectados es variada, tal efecto se ha sugerido podría deberse a condiciones ambientales a las cuales estuvieron sometidos los frutos (Ejiofor et al., 2018). En los trabajos de Talabi et al. (2016) y Ejiofor et al. (2018), las concentraciones de taninos, fitato y oxalato, se encuentran por arriba de 3,6 y $0.5 \mathrm{mg} / 100 \mathrm{~g}$, respectivamente. Tales cantidades de compuestos fueron consideradas tóxicas por Inuwa et al. (2011). Talabi et al. (2016) evaluaron el efecto de la maceración y el calentamiento sobre las concentraciones de nutrientes y antinutrientes de la SA. En su trabajo observaron que hervir la SA de 15 a 25 min, redujo el contenido de vitamina A $(16 \%)$ y $E(7 \%)$, mientras que la maceración tan solo redujo el contenido de la vitamina $A$ un $3 \%$. En la Tabla 6 se muestra la reducción de los antinutrientes en función del método de tratamiento.

Table 6. Effect of treatment method on avocado seed antinutrient reduction

Tabla 6. Efecto del método de tratamiento en la reducción de antinutrientes de la semilla de aguacate

\begin{tabular}{lcc}
\hline \multicolumn{1}{c}{ Compuesto } & Maceración (\%) & Calentamiento (\%) \\
\hline Taninos & 65 & 75 \\
Ácido fítico & 58 & 53 \\
Alcaloides & 64 & 79 \\
Saponinas & 48 & 21 \\
Oxalato & 49 & 32 \\
\hline
\end{tabular}

En la Tabla 6 se observa que la maceración y el calentamiento de la SA reduce la concentración de antinutrientes en la mayoría de los casos alrededor del $50 \%$. Sin embargo, es importante tener en consideración que aún en estas concentraciones, 
estos compuestos podrían causar una reacción desfavorable en personas sensibles a los mismos, ya que antinutrientes como el oxalato, en mínimas concentraciones pueden provocar ardor en ojos, oídos, boca y garganta (Natesh et al., 2017). Por la anterior, el estudio del efecto de la mezcla de los métodos reportados por Talabi et al. (2016) con otros métodos, como lavado, extrusión, hidrólisis térmica o enzimática, así como fermentación, que contribuyen a la reducción de antinutrientes, podría ser llevado a cabo con el objetivo de reducir aún más la presencia de estos fitoquímicos. Aunado a lo anterior, para el uso de derivados naturales, como es la SA, es necesario someterlos a evaluaciones toxicológicas y genotóxicas, que verifiquen su seguridad antes de ser empleados en la industria cosmética, alimentaria o farmacéutica (Meena et al., 2014). Ozolua et al. (2009) con el objetivo de determinar la DL50 en ratas de laboratorio, administraron una dosis de $2.5 \mathrm{~g} / \mathrm{Kg}$ de un extracto acuoso de SA durante 28 días. En las ratas administradas no se observaron signos de depresión, retorcimientos, diarrea, hipermotilidad o agresión. Tampoco se observaron cambios significativos en los parámetros hematológicos u órganos extraídos, así como en los marcadores de hepatotoxicidad como la alanina aminotransferasa (ALA) y aspartato aminotransferasa (AAM). Pahua-Ramos et al. (2012) reportaron que la harina de la SA presenta baja toxicidad; y Padilla-Camberos et al. (2013) determinaron una toxicidad aguda de $1200.75 \mathrm{mg} / \mathrm{Kg}$, para el extracto etanólico de la SA. El resultado del estudio de Zakariya et al. (2016) indica que la administración oral diaria de una solución acuosa del extracto acuoso y fenólico de semilla de $P$. americana, por un período de 3 semanas a una concentración de $500 \mathrm{mg} / \mathrm{Kg}$, generó un efecto hepatotóxico en los grupos administrados, ya que el análisis histopatológico del hígado mostró una degeneración y colapso de su arquitectura. Egbuonu \& Opara (2017) reportaron que un extracto etanólico de SA redujo los recuentos hematológicos y acerbo el efecto tóxico del glutamato monosódico en ratas, por lo que concluyen que es necesario realizar estudios adicionales sobre su uso para consumo de animales. La evaluación de las frecuencias de micronúcleos in vivo, es una de las principales pruebas de genotoxicidad recomendadas internacionalmente; y se ha sugerido que esta prueba debería usarse aun cuando no se observan signos de toxicidad a la concentración máxima posible (Liu et al., 2011). Considerando lo anterior, PadillaCamberos et al. (2013) evaluaron la inducción de micronúcleos de un extracto de $\mathrm{SA}$, sin detectar diferencias estadísticamente significativas, con respecto al control negativo, pero sí con respecto al control positivo. Por lo tanto, consideraron que el extracto no mostró actividad genotóxica.

Con los estudios sobre toxicidad de la SA hasta el momento realizados, no es claro si esta presenta toxicidad y si es así, el grado de la mismo, ya que tal efecto se sugiere podría estar en función de los compuestos extraídos de acuerdo al solvente o método de procesado de la SA, así como por las condiciones y frecuencia con que se consuma. 


\section{PATENTES}

El desarrollo y generación de conocimiento de uso inmediato, como son las aplicaciones biotecnológicas de la SA, previamente analizadas, presenta un potencial comercial que puede ser empleado por sus inventores. Esto ha impulsado el desarrollo de patentes como un método de protección de tal información. En la tabla 7 se muestran las patentes en las cuales se utiliza la SA como materia prima.

Table 7. Inventions in which the avocado seed are used

Tabla 7. Invenciones en las que es utilizada la semilla de aguacate

\begin{tabular}{|c|c|c|}
\hline Patente & $\begin{array}{c}\text { Año de } \\
\text { aplicación }\end{array}$ & Descripción \\
\hline US20120071551A1 & 2010 & $\begin{array}{l}\text { Generación de un extracto etanólico con } \\
\text { actividad miticida e insecticida contra } \\
\text { Panonychus citri, Oligonychus yothersi, } \\
\text { Tetranychus cinnabarinus, y Trialeurodes } \\
\text { vaporariorum }\end{array}$ \\
\hline USD245682S & 1975 & Aplicación en la producción de un vaso \\
\hline ES2378601B1 & 2010 & $\begin{array}{l}\text { Obtención de un extracto con propiedades } \\
\text { antioxidantes útil como aditivo antioxidante con } \\
\text { uso en la preparación de productos cárnicos y } \\
\text { alimenticios }\end{array}$ \\
\hline WO201 & 2014 & $\begin{array}{l}\text { Incorporación en un medio de cultivo para el } \\
\text { crecimiento y soporte de microalgas, hongos, } \\
\text { levaduras, musgos, bacterias y plantas }\end{array}$ \\
\hline CN106578204A & 2017 & Ingrediente en una bebida \\
\hline EP287a & 2013 & $\begin{array}{l}\text { Obtención de extractos de SA con ácidos } \\
\text { grasos polihidroxilados con aplicaciones } \\
\text { cosméticas y médicas }\end{array}$ \\
\hline MX2014001229 & 2014 & Componente principal en un shampoo \\
\hline PH22017000681Y1 & 2017 & Ingrediente en galletas \\
\hline WO2016101052A1 & 2014 & $\begin{array}{l}\text { Selección de fracciones hidroalcohólicas que se } \\
\text { pueden incorporar en insecticidas }\end{array}$ \\
\hline US20130 & 2009 & $\begin{array}{l}\text { Producción de un adsorbente para la } \\
\text { eliminación de contaminantes presentes en } \\
\text { aguas residuales }\end{array}$ \\
\hline
\end{tabular}


US9416333B2 2012

CN107603781A 2017

US20140303114A1 2010

FR2075994A1 1970

RU2014133099A 2012

CN107522684A 2017

CN104523836A 2014

CN106578204A 2017
Materia para la generación de un aceite enriquecido en alquilpolioles y derivados acetilados, para uso en la prevención y tratamiento de trastornos del tejido conjuntivo como artrosis, y patologías articulares como reumatismo 0 enfermedades periodontales como la gingivitis o la periodontitis Ingrediente en un jabón con propiedades bacteriostáticas, que no genera irritación, y permite que la piel se humecte, alise, y no se seque

Materia para la extracción de compuestos derivados de furano con actividad repelente y miticida contra Tetranychus urticae, Tetranychus cinnabarinus, Oligonychus yothersi, Panonychus citri, y Brevipalpus chilensis

Materia para la obtención de trihidroxi heptadecano con actividad bactericida activo contra $B$. subtilis y $S$. aureus

Obtención de aceite enriquecido con alcoholes polihídricos alifáticos y sus derivados acetilados Fuente de procianidina B2 con capacidad de generar un efecto hipoglucémico y eliminación de radicales libres

Materia para la producción de proteínas, polisacáridos y polifenoles

Obtención de un té reductor de grasa corporal empleado para la perdida de peso

La búsqueda de patentes se realizó en la base de datos Espacenet, google patents y FreePatentsOnline (FPO), empleando como términos de búsqueda "semilla", "aguacate", "semilla de aguacate", y su combinación con los términos de cada subtítulo. El período de búsqueda estuvo comprendido entre 1950 y 2020. Como resultado se encontraron 180 patentes, de las cuales de acuerdo al enfoque de la revisión se seleccionaron 16. La primera patente registrada con alguna aplicación de la SA fue en el año de 1975. De las patentes seleccionadas el $81 \%$ fueron aplicadas a partir del año 2010, lo que nos muestra la creciente tendencia hacia la protección de la información generada mediante la investigación de la SA, lo anterior en su mayoría, para el desarrollo comercial de tales invenciones. 


\section{CONCLUSIÓN}

Como se muestra en la presente revisión, la SA presenta propiedades que le permiten desde ser incorporada en alimentos funcionales, que generan una reducción de radicales libres debido a su capacidad antioxidante, producida principalmente por su concentración de catequinas; así como de control de glucosa, colesterol e hipertensión, con potencial como anticancerígeno en el tratamiento de cáncer de mama, pulmón, colon y próstata. La aplicación de la SA en la industria alimentaria se ve favorecida por el efecto antimicrobiano de la misma y por su contribución en la textura de los alimentos, principalmente debido a la cantidad de fibra y almidón que presenta la misma. Estas últimas propiedades, permiten que la SA sea un excelente absorbente de compuestos tóxicos y una fuente potencial para la producción de azúcares fermentables en la generación de biocombustibles y bioplásticos. Como tendencia, se observa la generación de un colorante con propiedades antioxidantes y su empleo en la formulación de medios de crecimiento de microorganismos, sin dejar de considerar su potencial aplicación como composta. Sin embargo, aun cuando los estudios indican que la toxicidad de ciertos fitoquímicos esta en función de su concentración y biotransformación, en este documento se recomienda su procesamiento con los métodos de desnaturalización de fitoquímicos planteados, lo anterior con el fin de reducir y/o eliminar posibles compuestos tóxicos detectados. De acuerdo al análisis de las variadas aplicaciones biotecnológicas de la SA aquí planteadas, podemos considerar a este residuo agroindustrial con un amplio potencial económico a desarrollar.

\section{AGRADECIMIENTOS}

Se agradece al Centro de Innovación y Desarrollo Agroalimentario de Michoacán A.C., por el apoyo para la realización del presente manuscrito.

\section{CONFLICTO DE INTERESES}

No existen conflictos de intereses

\section{REFERENCIAS}

Abebe R. W., Yenework N. A., \& Yeshitila A.T. 2015. Bioethanol production from avocado seed wastes using Saccharomyces cerevisiae. American Journal of Environment, Energy and Power Research. 3(1):1-9.

Abubakar A. N. F., Achmadi S. S., \& Suparto I. H. 2017. Triterpenoid of avocado (Persea americana) seed and its cytotoxic activity toward breast MCF-7 and liver HepG2 cancer cells. Asian Pacific Journal of Tropical Biomedicine. 7(5):397-400.

Abdel-Moneim A., Osama M., Ahmed H. I., Fahim E., \& Mohamed E. 2017. The preventive effects of avocado fruit and seed extracts on cardio-nephrotoxicity induced by diethylnitrosamine/2-acetylaminoflurine in wistar rats. Basic Sciences of Medicine. 6(1):4-13. 
Adesina J. M., Jose A. R., Rajashekar Y., \& lleke K. D. 2016. Persea americana (Mill.) seed extracts: Potential herbal larvicide control measure against Anopheles gambiae Giles, 1902 (Diptera: Culicidae). Malaria Vector. 3(2):14-17.

Aditiya H. B., Mahlia T. M. I., Chong W. T., Nur H., \& Sebayang A. H. 2016. Second-generation bioethanol production: A critical review. Renewable and Sustainable Energy Reviews. 66:631-653.

Ahmed N., Smith R.W., Henao J. J. A., Stark K. D., Spagnuolo P.A. 2018. Analytical method to detect and quantify Avocatin B in Hass Avocado Seed and pulp matter. Journal of Natural Products. 81:818-824.

Alissa K., Yu-Chi Hung., Chih Y. H., GiGi C., Wen L., \& Jhih-Ying C. 2020. Developing new health material: The utilization of spray drying technology on avocado (Persea Americana Mill.) seed powder. Foods. 9(139);1-15.

Alkhalf, M. I., Alansari, W. S., Ahmed-lbrahim, E., \& ELhalwagy, M. E. A. 2018. Anti-oxidant, antiinflammatory and anti-cancer activities of avocado (Persea americana) fruit and seed extract. Journal of King Saud University - Science. 8:426-479.

Álvarez A., Pizarro C., García R., \& Bueno J. L. 2015. Spanish biofuels heating value estimation based on structural analysis. Industrial Crops and Products. 77:983-991.

Alves-Silva I. R., Magnani M., Medeiros de Albuquerque F. M., Batista K. S., Aquino J. S., \& Queiroga-Neto V. 2017. Characterization of the chemical and structural properties of native and acetylated starches from avocado (Perseaamericana Mill.) seeds. International Journal of Food Properties. 20:279289.

Araújo R. G., Rodriguez-Jasso R. M., Ruiz H. A., Pintado M. M. E., \& Aguilar C.N. 2018. Avocado by-products: nutritional and functional properties. Trends in Food Science \& Technology. 80:51-60.

Ariestya A., Prima K., Utama L., Anggraini S. 2015. The preliminary study of the dye extraction from the avocado seed using ultrasonic assisted extraction. Procedia Chemistry. 16:334-340.

Athaydes B. R., Alves G. M., de Assis, A. L. E. M., Gomes J. V. D., Rodrigues R. P., Campagnaro B. P., Nogueira B. V., Silveira D., Kuster R. M., \& Pereira T. M. C. 2019. Avocado seeds (Persea americana Mill.) prevents indomethacin-induced gastric ulcer in mice. Food Research International. 119:751-760.

Báez-Magaña M., Ochoa-Zarzosa A., Alva-Murillo N., Salgado-Garciglia R., \& López-Meza J.E. 2019. Lipid-rich extract from Mexican avocado seed (Persea americana var. drymifolia) reduces Staphylococcus aureus internalization and regulates innate immune response in bovine mammary epithelial cells. Journal of immunology research. 1-10. 
Bahru T. B., Tadele Z. H., \& Ajebe E. G. A. 2019. Review on avocado seed: Functionality, composition, antioxidant and antimicrobial properties. International Journal of Chemical Sciences. 7(2):1-10.

Bahry H., Pons A., Abdallah R., Pierre G., Delattre C., \& Fayad N. 2017. Valorization of carob waste: Definition of a second-generation bioethanol production process. Bioresource Technology. 235:25-34.

Barbosa-Martín E., Chel-Guerrero L., Gonzalez-Mondragón E., \& Betancur-Ancona D. 2016. Chemical and technological properties of avocado (Persea americana Mill.) seed fibrous residues. Food and Bioproducts Processing. 100:457-463.

Bangerth K.F. 2008. Possible interferences of pre-harvest factors with the storage behaviour and quality of fruit. Acta Hortic. 796:19-29. DOI: 10.17660/ActaHortic.2008.796.1 https://doi.org/10.17660/ActaHortic.2008.796.1

Bazzo A. M. A., Adebayo S. L. P., Dias E. C., Lima J. C. P., Vaghetti E. R., Oliveira A. J. B. Leite F. \& Pavan A. 2015. Avocado seed powder: Characterization and its application for crystal violet dye removal from aqueous solutions, desalination and water treatment journal. 57:15873-15888.

Bereded F. S. 2019. Extraction of oil and phenolic retanning agent from avocado seed. Environmental Analyses and Ecological Studies. 4(5):437- 448.

Bhaumik M., Choi H. J., Seopela M. P., McCrindle R. I. \& Maity A. 2014. Highly effective removal of toxic $\mathrm{Cr}(\mathrm{VI})$ from wastewater using sulfuric acid-modified avocado seed. Industrial and Engineering Chemistry Research. 53:1214-1224.

Bronick C. J., \& Lal R. 2005. Soil structure and management: A review. Geoderma. 124(2):3-22.

Camberos E., Velázquez M., Fernández J. M., \& Rodríguez S. 2013. Acute toxicity and genotoxic activity of avocado seed extract (Persea americana Mill., c.v. Hass). The Scientific World Journal. 1-4.

Cardoso P. F., Scarpassa J. A., Pretto L. G., Otaguiri E. S., Yamada S. F., \& Nakazato G. 2016. Antibacterial activity of avocado extracts (Persea americana Mill.) against

Streptococcus

agalactiae. International Journal of Experimental Botany. 85(2):218-224

Chel-Guerrero L., Barbosa-Martín E., Martínez-Antonio A., González-Mondragón, E. \& Betancur-Ancona D. 2016. Some physicochemical and rheological properties of starch isolated from avocado seeds. International Journal of Biological Macromolecules. 86:302-308.

Colombo R., \& Papetti A. 2019. Avocado (Persea americana Mill.) by-products and their impact: From bioactive compounds to biomass energy and sorbent material for removing contaminants. A review. International Journal of Food Science and Technology. 54: 1-9. 
Cornelia M., \& Christianti A. 2018. Utilization of modified starch from avocado (Persea americana Mill.) seed in cream soup production. IOP Conf. Series: Earth and Environmental Science. 102

Dabas D., Elias R. J., Lambert J. D. \& Ziegler G.R. 2011. A colored avocado seed extract as a potential natural colorant. Journal of Food Science. 76:1335-1341.

Dabas D., Elias R. J., Ziegler G. R., \& Lambert J. D. 2019a. In vitro antioxidant and cancer inhibitory activity of a colored avocado seed extract. International Journal of Food Science. 1-7.

Dabas D., Ziegler G. R., Lambert J. D. 2019b. Anti-inflammatory properties of a colored avocado seed extract. Adv Food Technol Nutr Sci Open J. 5(1): 8-12.

Dagde K. K. 2019. Extraction of vegetable oil from avocado seeds for production of biodiesel. Journal of Applied Sciences and Environmental Management. 23 (2):215-221.

Daihan S., Aldbass A. M., Alotebi L. M., \& Bhat R. S. 2016. Antioxidant and antimicrobial activity of whole seed extracts of Persea americana Mill. Indian Journal of Pharmaceutical and Biological Research. 4(4):15-18.

Dávila-Jiménez M. M., Elizalde-González M. P., García-Díaz M., Marín-Cevada V., \& Zequineli-Pérez J. 2015. Photodegradation of the anthraquinonic dye acid green 25 by $\mathrm{TiO}_{2}$ immobilized on carbonized avocado kernels: Intermediates and toxicity. applied catalysis B: Environmental. 166-167:241-250.

Deepalakshmi S., Sivalingam A., Thirumarimurugan M., Yasvanthrajan N. \& Sivakumar P. 2014. In-situ transesterification and process optimization of biodiesel from waste avocado seed. Journal of Chemical and Pharmaceutical Sciences. $4: 115-118$.

Dennis CN, \& Wulandari S. 2017. Antibacterial effect of ethanol extract of the avocado seed (Persea americana Mill.) as an alternative root canal Irrigants against Porphyromonas Gingivalis (in vitro). International Journal of Applied Decision Sciences. 3(1):89-93.

Devi R. 2010. Innovative technology of COD and BOD reduction from coffee processing wastewater using avocado seed carbon (ASC). Water Air Soil Pollution. 207:299-306.

Dharmaratne H., Tekwani B., Jacob M., \& Nanayakkara N. 2012. Anti-microbial and antileishmanial active acetogenins from Avacado (Persea americana) fruits. Planta Medica Journal. 78:34-42.

Domínguez M. P., Araus K., Bonert P., Sanchez F., Miguel G. S., \& Toledo M. 2014. The avocado and its waste: An approach of fuel potential/application. In G. Lefebvre, G. Jiménez, B. Cabañas (Eds.). Environment, energy and climate change II: Energies from new resources and the climate change (pp. 199-223). Switzerland: Springer International Publishing. 
Dreher M.L. \& Davenport A.J. 2013. Hass avocado composition and potential health effects. Critical Reviews in Food Science and Nutrition. 53:738-750.

Durak H. \& Aysu T. 2015. Effect of pyrolysis temperature and catalyst on production of bio-oil and bio-char from avocado seeds. Research on Chemical Intermediate. 41:8067-8097.

Egbuonu A. C. C., \& Opara C. I. 2017. Avocado pear (Persea Americana) seed flour 1: Some mineral contents and effect of the ethanolic extract on the hematology of normal and monosodium glutamate-intoxicated rats. Journal of Food Nutrition and Population Health.1:3-23.

Egbuonu A. C. C., Opara I. C., Onyeabo C., \& Uchenna N. O. 2018. Proximate, functional, antinutrient and antimicrobial properties of avocado pear (Persea americana) seeds. Journal of Nutritional Health \& Food Engineering. 1:78-82.

Ejiofor N. C., Ezeagu I. E., Ayoola M., \& Umera E. A. 2018. Determination of the chemical composition of avocado (Persea americana) seed. Advances In Food Technology and Nutritional Sciences. 2: 51-55.

Elango G., Kumaran S. M., Kumar S. S., Muthuraja S., Roopan S. M. 2015. Green synthesis of $\mathrm{SnO}_{2}$ nanoparticles and its photocatalytic activity of phenolsulfonphthalein dye. Spectrochimica Acta Past A. 145:176-180.

El-Sayed, H.E. \& El-Sayed, M.M. 2014. Assessment of food processing and pharmaceutical industrial wastes as potential biosorbents: a review. BioMed Research International.

Essack H., Odhav B., \& Mellem J. J. 2017. Screening of traditional South African leafy vegetables for selected anti-nutrient factors before and after processing. Food Science and Technology. 3:462-471.

Fagundes M. C. P., De Oliveira A. F., De Carvalho V. L., Ramos J. D., Dos Santos, V. A., \& Rufini J. M. 2018. Alternative control of plant pathogen fungi through ethanolic extracts of avocado seeds (Persea Americana Mill.). Brazilian Archives of Biology and Technology. 61:1-9.

Fan Y., Guo D. Y., Song Q., \& Li T. 2013. Effect of total saponin of aralia taibaiensis on proliferation of leukemia cells. Zhong Yao Cai. 36(4): 604-607.

Falodun A., Erharuyi O., Imieje V., Ahomafor J., Akunyuli C., Jacobs M. Khan S., Hamann M.T. \& Langer P. 2014. In vitro evaluation of aliphatic fatty alcohol metabolites of Persea americana seed as potential antimalarial and antimicrobial agents. Nigerian Journal of Biotechnology. 27:1-7.

FAOSTAT, 2014. Food and agriculture organization of the United Nations. Agriculture Database http://www.fao.org/faostat/en/\#data/QC, (consultado diciembre 10, 2019) 
Fernández-Castañeda L. A., Arias-Candamil H., Zapata-Torres B. \& ArdilaCastañeda M.P. 2018. Evaluation of the antimicrobial capacity of Hass avocado seed extract (Persea americana) for potential application in the meat industry. DYNA Ingeniería e Industria. 85(207):346-350.

Figueroa J. G., Borrás-Linares I., Lozano-Sánchez J., \& Segura-Carretero A. 2018. Comprehensive characterization of phenolic and other polar compounds in the seed and seed coat of avocado by HPLC-DAD-ESI-QTOF-MS. Food Research International. 105:752-763

Ge Y., Cheng Z. H., Si X. Y., Ma W. H., Tan L., Zang X. P., Wu B., Xu Z. N., Wang N., \& Zhou Z. X. 2019. Transcriptome profifiling provides insight into the genes in carotenoid biosynthesis during the mesocarp and seed developmental stages of avocado (Persea Americana). International Journal of Molecular Sciences. 20:4117-4136.

Gemede H. F., \& Ratta N. 2014. Antinutritional factors in plant foods: potential health benefits and adverse effects. International Journal of Nutrition and Food Sciences. 3(4):284-289.

Gidigbi J. A., Ngoshe A. M. \& Aisuedion M. 2019. Industrial viability study of the avocado seed oil. International Journal of Recent Innovations in Academic Research. 3(6):48-57.

Ginting M. H., Hasibuan R., Lubis M., Alanjani F., Winoto F., \& Siregar R.C. 2018. Supply of Avocado Starch (Persea Americana Mill) as Bioplastic Material. 309: 1-6.

González-Fernández J. J., Galea Z., Álvarez J. M., Hormaza J. I., \& López R. 2015. Evaluation of composition and performance of composts derived from guacamole production residues. Journal of Environmental Management. 147:132139.

Gupta R. K., Gangoliya S. S., \& Singh N. K. Reduction of phytic acid and enhancement of bioavailable micronutrients in food grains. Journal of Food Science and Technology. 52(2):676-84.

Gusti, D. R. Lestari I. Farid F. Sirait P. T. 2019. Protection of mild steel from corrosion using methanol extract of avocado (Persea americana Mill) seeds in a solution of sulfuric acid. Journal of Physics. 1282:1-8.

Hatzakis E., Mazzola E. P., Shegog R. M., Ziegler G. R., Lambert J. D. 2019. Perseorangin: A Natural Pigment from Avocado (Persea americana) Seed. Food Chemistry. 30:15-22.

Henry L. N., Mtaita U. Y., \& Kimaro C. C. 2015. Nutritional efficacy of avocado seeds. Global Journal of Food Science and Technology. 3(5):192-196. 
Hershkovitz V., Friedman H., Goldschmidt E., \& Pesis E. 2010. Ethylene regulation of avocado ripening differs between seeded and seedless fruit. Postharvest Biology and Technology. 56(2):138-146.

Hiwot T. 2017. Determination of oil and biodiesel content, physicochemical properties of the oil extracted from avocado seed (Persea americana) grown in Wonago and Dilla (Gedeo zone) Southern Ethiopia. Chemistry International. 3(3): 311-319.

Ifesan B. O., Olorunsola B. O., \& Ifesan B. T. 2015. Nutritional composition and acceptability of candy from avocado seed (Persea americana). International Journal of Agriculture Innovations and Research. 3(6):2319-1473.

Imafidon K. E., \& Amaechina F. C. 2010. Effects of aqueous seed extract of Persea americana Mill. (Avocado) on blood pressure and lipid profile in hypertensive Rats. Advances in Biological Research. 4(2):116-121.

Inuwa H. M., Aina V. O., Gabi B., Aimola I., \& Toyin A. 2011. Comparative determination of antinutritional factors in groundnut oil and palm oil. Advance Journal of Food Science and Technology. 3(4):275-279.

Jayaprakasha G. K., Selvi T., \& Sakariah K. K., 2003. Antibacterial and antioxidant activities of grape (Vitis vinifera) seed exstracts. Food Research International. 36: 117-122.

Jiménez-Arellanes A., Luna-Herrera J., Ruiz-Nicolás R., Cornejo-Garrido J., Tapia A., \& Yépez-Mulia L. 2013. Antiprotozoal and antimycobacterial activities of Persea americana seeds. BMC Complementary and Alternative Medicine. 13:109-114.

Jiru K, \& Urga K. 1995. Forms and contents of oxalate and calcium in some vegetables in Ethiopia. Ethiopian Journal of Health Development. 9(1):13-18.

Kant R., 2012. Textile dyeing industry an environmental hazard. Natural Sciences. 4:22-26.

Kaur S., Rani S., \& Mahajan R.K. 2015. Adsorption of dye crystal violet onto surface-modifified Eichhornia crassipes, desalin. Water Treat. 53:1957-1969.

Kosinska A., Karamac M., Estrella I., Hernández T., Bartolome B., \& Dykes G.A. 2012. Phenolic compound profiles and antioxidant capacity of Persea americana Mill. Peels and seeds of two varieties. Journal of Agricultural and Food Chemistry. 60:4613-4619.

Kowalski R. L., Schneider V. S., Moretto J., \& Gomes L. F. S. 2017. Producao de etanol de segunda geracao a partir de caroco de abacate (Persea americana Mill.). Revista Brasileira de Energias Renováveis. 6(4):665-677. 
Kristanti C. D., Simanjuntak F. P., Dewi K. P., Tianri S. V., \& Hendra P. 2017. Antiinflammatory and analgesic activities of avocado seed (Persea americana Mill.) Jurnal farmasi sains dan komunitas. 14(2):104-111.

Kunatsa Y., Chidewe C., \& Zvidzai C.J. 2020. Phytochemical and anti-nutrient composite from selected marginalized Zimbabwean edible insects and vegetables. Journal of Agriculture and Food Research. 2:1-6.

Kunow M. A. 2003. Plant Catalog: Appendix A. In: Kunow, M. A., editor. Maya medicine:traditional healing in Yucatan. Albuquerque: University of New Mexico Press. p. 129.

Lacerda L. G., Da Silva C. F. M. A., Bauab T., Demiate I. M., Colman T. A. D., Andrade M. M. P. 2015. The effects of heat-moisture treatment on avocado starch granules: Thermoanalytical and structural analysis. Journal of Thermal Analysis and Calorimetry. 120(1):387-393.

Leege P.B. 1998. Introduction of thest methods for the examination of composting and f compost. In S. L. Brown, J. S. Angle, and L.W. Jacobs (eds.) Benefical coutilization of agricultural, municipal and industrial by-products. Nehterlands: Springer. Pp. 269-282.

Leite J. J. G., Brito É. H. S., Cordeiro R. A., Brilhante R. S. N., Sidrim J. J. C., Bertini L. M. 2009. Chemical composition, toxicity and larvicidal and antifungal activities of Persea americana (avocado) seed extracts. Revista da Sociedade Brasileira de Medicina Tropical. 42(2):110-113.

Leite A. B., Saucier C., Lima E. C., Dos Reis G. S., Umpierres C. S., Mello B. L., Shirmardi M., Dias S. L. P., \& Sampaio C. H. 2018. Activated carbons from avocado seed: optimisation and application for removal of several emerging organic compounds. Environmental Science and Pollution Research. 25(8):76477661.

López-Cobo A., Gómez-Caravaca A. M., Pasini F., Caboni M. F., Segura-Carretero A., \& Fernández-Gutiérrez A. 2016. HPLC-DAD-ESI-QTOF-MS and HPLC-FLDMS as valuable tools for the determination of phenolic and other polar compounds in the edible part and by-products of avocado. Lebensmittel-Wissenschaft und Technologie-Food Science and Technology. 73:505-513.

Liu W., Giorgio C., Lamidi M., Elias R., \& Ollivier E. 2011. "Genotoxic and clastogenic activity of saponins extracted from Nauclea bark as assessed by the micronucleus and the comet assays in Chinese Hamster Ovary cells,". Journal of Ethnopharmacology. 137(1):176-183

Lu Y. C., Chang H. S., Peng C. F., Lin C. H., \& Chen I. S. 2012. Secondary metabolites from the unripe pulp of Persea americana and their antimycobacterial activities. Food Chemistry. 135(4):2904-2909. 
Lubis M., Harahap M. D., Manullang A., Ginting M. H. S. Sartika M. 2014. Utilization starch of jackfruit (Atrocarpus herephyllus) as raw material for bioplastics manufacturing using sorbitol as plasticizer and chitosan as filter. Waste Management \& Research. 40(3):105-199.

Lubis M., Harahap M. B., Ginting M. H. S., Sartika M., \& Azmi H. 2018. Production of bioplastic from avocado seed starch reinforced with microcrystalline cellulose from sugar palm fibers. Journal of Engineering Science and Technology. 13:381393

Mahawan M. A., Tenorio F. N., Gómez J. A., \& Bronce R. A. 2015. Characterization of flour from avocado seed kernel. Asia Pacific Journal of Multidisciplinary Research. 3(4):34-40.

Meena A. K., Jain A., Pandey K., Singh R. K. 2014. Acute toxicity and genotoxic activity of Hibiscus rosasinensis flower extract. American Journal of Phytomedicine and Clinical Therapeutics. 2(4):524-529.

Melgar B., Dias M. I., Ciric A., Sokovic M., Garcia-Castello E. M., Rodriguez-Lopez A. D., Barros L., \& Ferreira I. C. 2018. Bioactive characterization of Persea americana Mill. by-products: A rich source of inherent antioxidants. Industrial Crops and Products. 111:212-218.

Morton J. F, \& Dowling C. F. 1987. Avocado. Fruits of warm cliate. Miami, FL; Winterville, N.C.: J.F. Morton. p. 91-102.

Mugdil D., \& Barak S. 2013. Composition, properties and health benefits of indigestible carbohydrate polymers as dietary fiber: a review. International Journal of Biological Macromolecules. 61:1-6.

Muneer F. 2014. Bioplastics from natural polymers. Introductory Paper at the Faculty of Landscape Architecture, Horticulture and Crop Production Sciences, Alnarp. 4:1-10.

Natesh H. N., Abbey L., \& Asiedu S. K. 2017. An overview of nutritional and antinutritional factors in green leafy vegetables. Horticulture International Journal. 1(2):58-65.

Nwaogu L. A., Alisi C. S. \& Ojiako, O. A. 2008. Studies on the nutritional and phytochemical properties of Persea americana seed. Bio-research. 6(1):320-322.

Oboh G., Odubanjo V. O., Bello F., Ademosun A. O., Oyeleye S. I., Nwanna E. E., \& Ademiluyi A. O. 2016. Aqueous extracts of avocado pear (Persea americana Mill.) leaves and seeds exhibit anticholinesterases and antioxidant activities in vitro. Journal of Basic and Clinical Physiology and Pharmacology. 27:131-140. 
Omolara O. O., Friday O. N., \& Chinelo M. O. 2017. Comparative study of the constituents of the fruits pulps and seeds of Canarium ovatum, Persea americana and Dacryodes edulis. Journal of Chemistry. 12(2):113-125.

Ortega-Arellano H. F., Jimenez-Del-Rio M., \& Velez-Pardo C. 2019. Neuroprotective effects of methanolic extract of avocado Persea americana (var. Colinred) peel on paraquat-induced locomotor impairment, lipid peroxidation and shortage of life span in transgenic knockdown parkin Drosophila melanogaster. Neurochemical Research. 44:1986-1998.

Ortiz M. A., Dorantes A. L., Galindez M. J., \& Cárdenas S. E. 2004. Effect of a novel oil extraction method on avocado (Persea americana Mill) pulp microstructure. Plant Foods for Human Nutrition. 59(1):11-14.

Ospina S., Restrepo D., \& López J. 2011. Caracterización microbiológica y bromatológica de hamburguesas bajas en grasa con adición de fibra de banano verde integro. Revista Facultad Nacional de Agronomía Medellín. 64(1):59936005.

Ozolua R. I., Anaka O. N., Okpo S. O., \& Idogun S. E. 2009. Acute and sub-acute toxicological assessment of the aqueous seed extract of Persea americana Mill (Lauraceae) in rats. African Journal of Traditional, Complementary, and Alternative Medicine. 6(4):573-578.

Pacheco A., Rodríguez-Sánchez D. G., Villarreal-Lara R., Navarro-Silva J. M., Senés-Guerrero C., \& Hernández-Brenes C. 2017. Stability of the antimicrobial activity of acetogenins from avocado seed, under common food processing conditions, against Clostridium sporogenes vegetative cell growth and endospore germination. International Journal of Food Science \& Technology. 52:2311-2323.

Padilla-Camberos E., Martínez-Velázquez M., Flores-Fernández, J.M. \& Villanueva-Rodríguez, S. 2013. Acute toxicity and genotoxic activity of avocado seed extract (Persea americana Mill., c.v. Hass). The Scientific World Journal. 10:1-4.

Pahua-Ramos M. E., Ortiz-Moreno A., Chamorro-Cevallos G., Hernández-Navarro M. D., Necoechea-Mondragón H., \& Hernández-Ortega, M. 2012. Hypolipidemic effect of avocado (Persea americana Mill) seed in a hypercholesterolemic mouse model. Plant Foods for Human Nutrition. 67:10-16.

Palmerín-Carreño D. M., Hernández-Orihuela A. L., \& Martínez-Antonio A. 2019. Production of D-lactate from avocado seed hydrolysates by metabolically engineered Escherichia coli JU15. Fermentation. 5:26-35.

Pavan F. A., Camacho E. S., Lima E. C., Dotto G. L., Branco V. T. A., \& Dias S. L. P., 2014. Formosa papaya seed powder (FPSP): preparation, characterization and application as an alternative adsorbent for the removal of crystal violet from aqueous phase. Journal of Environmental Chemical Engineering. 2:230-238. 
Perea-Moreno A. J., Aguilera-Urena M. J. \& Manzano-Agugliaro F. 2016. Fuel properties of avocado stone. Fuel. 186:358-364.

Popova A., \& Mihaylova D. 2019. Antinutrients in plant-based foods: A review. The Open Biotechnology Journal. 13:68-76.

Pushkar S. B., Narendra N., Rocha R. V. M., \& Marcal Q. P. 2001. Characterization of the oils from the pulp and seeds of avocado (Cultivar: Fuerte) fruits. Grasas y Aceites. 3(4):171-174.

Rachimoellah H., Resti D. A., Zibbeni A. \& Wayan S. I. 2010. "Production of biodiesel through transesterification of avocado (Persea gratissima) seed oil using base catalyst". Jurnal Teknik Mesin. 11(2):85-90.

Raymond T. W. C. \& Dykes A. G. 2010. Antimicrobial activity of crude epicarp and seed extracts from mature avocado fruit (Persea americana) of three cultivars. Pharmaceutical Biology. 48(7):753-756.

Ren X., Xiao W., Zhang R., Shang Y., \& Han R. 2015. Adsorption of crystal violet from aqueous solution by chemically modified phoenix tree leaves in batch mode. Desalination and Water Treatment. 53:1324-1334.

Rivera-González G., Amaya-Guerra C. A., \& de la Rosa-Millán J. 2019. Physicochemical characterisation and in vitro starch digestion of avocado seed flour (Persea americana V. Hass) and its starch and fibrous fractions. International journal of food science \& technology. 54:2447-2457.

Rodriguez-Carpena J. G., Morcuende D., \& Estevez M. 2011 a. Avocado byproducts as inhibitors of color deterioration and lipid and protein oxidation in raw porcine patties subjected to chilled storage. Meat Science. 89:166 -73.

Rodríguez-Carpena J. G., Morcuende D., Andrade M. J., Kylli P., \& Estévez M. 2011 b. Avocado (Persea americana Mill.) phenolics, in vitro antioxidant and antimicrobial activities, and inhibition of lipid and protein oxidation in porcine patties. Journal of Agricultural and Food Chemistry. 59:5625-5635.

Rodríguez-Sánchez D. G., Pacheco A., Villarreal-Lara R., Ramos-González M. R., Ramos-Parra P. A., Granados-Principal S., Díaz de la Garza R. I., García-Rivas G., \& Hernández-Brenes C. 2019. Chemical profile and safety assessment of a food-grade acetogenin-enriched antimicrobial extract from avocado seed. Molecules. 24(13):2354-2381.

Roger C.R. 1999. The nutritional incidence of flavonoids: some physiological and metabolic considerations. Experientia. 44(9):725-733.

Rosenblat G., Kagan H. M., Shah M. A., Spiteller G., \& Neeman I. 1995. Chemical characterization of lysyl oxidase inhibitor from avocado seed oil. Journal of the American Oil Chemists' Society. 72:225-229. 
Rosenblat G., Meretski S., Segal J., Tarshis M., Schroeder A., \& Gilead A. Z. 2011. Polyhydroxylated fatty alcohols derived from avocado suppress inflammatory response and provide non-sunscreen protection against UV-induced damage in skin cells. Archives of Dermatological Research. 303:239-246.

Rosero J. C., Cruz S., Osorio C., \& Hurtado N. 2019. Analysis of phenolic composition of byproducts (seeds and peels) of avocado (Persea americana Mill.) cultivated in colombia. Molecules. 24(17):3209-3226.

Salinas-Salazar C., Hernández-Brenes C., Rodríguez-Sánchez D. G., Castillo E. C., Navarro-Silva J. M., \& Pacheco A. 2017. Inhibitory activity of avocado seed fatty acid derivatives (Acetogenins) against Listeria monocytogenes. Journal of Food Science. 82(1):134-144.

Sánchez F., Araus K., Domínguez M. P. \& San Miguel G. 2017. Thermochemical transformation of residual avocado seeds: torrefaction and carbonization. Waste Biomass Valorization. 8:2495-2510.

Segovia F., Peiro S. S., Gallego I. M.G., Mohd A. N.A. \& Pilar A. M. 2014. Avocado seeds: extraction optimization and possible use as antioxidant in food. Antioxidants. 3:439-454.

Segovia F., Corral-Pérez J. J., \& Almajano M. P. 2016. Avocado seed: modeling extraction of bioactive compounds. Industrial Crops and Products. 85:213-220.

Segovia F., Hidalgo G., Villasante J., Ramis X., \& Almajano M. 2018. Avocado seed: A comparative study of antioxidant content and capacity in protecting oil models from oxidation. Molecules. 23:2421-2435.

SIAP (2015). Servicio de Información Agroalimentaria y Pesquera. http://infosiap.siap.gob. mx/aagricola_siap_gb/ientidad/index.jsp, Accessed date: 21 August 2019.

Soong Y. Y., \& Barlow P. J. 2004. Antioxidant activity and phenolic content of selected fruit seeds. Food Chemistry. 88(3):411-417.

Talabi J. Y., Olukemi A., Osukoya O. O., \& Ajayi A. G. O. 2016. Nutritional and antinutritional compositions of processed Avocado seeds. Asian Journal of Plant Science and Research. 6(2):6-12.

Tesfaye T., Gibril M., \& Sithole B. 2018. Valorisation of avocado seeds: extraction and characterisation of starch for textile applications. Clean Technologies Environmental Policy. 20:2135-2154.

Tremocoldi M. A., Rosalen P. L., \& Franchin M. 2018. Exploration of avocado byproducts as natural sources of bioactive compounds. PLoS One. 13(2):1-12. 
Tugiyanti E., Iriyanti N., \& Apriyanto Y. S. 2019. The effect of avocado seed powder (Persea americana Mill.) on the liver and kidney functions and meat quality of culled female quail (Coturnix coturnix japonica). Veterinary world. 12(10):16081615.

Tzintzun-Camacho O., Sánchez-Segura L., Minchaca-Acosta A. Z., RosalesColunga L. M., Hernández-Orihuela A. L., Martínez-Antonio A. 2016. Development of bacterial culture medium from avocado seed. Revista Mexicana de Ingeniería Química. 15:831-842.

Uchenna U. E., Shori A. E., \& Baba A. S. 2017. Inclusion of avocado (Persea americana) seeds in the diet to improve carbohydrate and lipid metabolism in rats. Revista Argentina Endocrnología y Metabolismo. 54(3):140-148.

Villarreal-Lara R., Rodriguez-Sanchez G., Diaz D., Garcia-Cruz I., Castillo A., Pacheco A., \& Hernandez-Brenes C. 2019. Purified avocado seed acetogenins: Antimicrobial spectrum and complete inhibition of Listeriamonocytogenes in a refrigerated food matrix, CyTA. Journal of Food. 17:(1):228-239.

Wang W., Bostic T. R., \& Gu L. 2010. Antioxidant capacities, procyanidins and pigments in avocados of different strains and cultivars. Food Chemistry. 122(4): 1193-1198.

Wangensteen H., Samuelsen A. B., \& Malterud K. E. 2004. Antioxidant activity in extracts from coriander. Food Chemistry. 88 (2):293-297.

Werman M. J., \& Neeman M. S. 1990. Partial isolation and characterization of a new natural inhibitor of lysyl oxidase from avocado seed oil. Journal of Agricultural and Food Chemistry. 38:2164-2166.

Werman M. J., Mokady S., Nimni M. E., \& Neeman I. 1991. The effect of various avocado oils on skin collagen metabolism. Connective Tissue Research. 26:1-10.

Woldu A. R., \& Tsigie Y.A. 2015. Optimization of hydrolysis for reduced sugar determination from avocado seed wastes. Amercian Journal of Energy and Environmental. 3:1-10.

Yaakobovich Y., \& Neeman I. 1983 Partial isolation and characterization of a hemagglutinating factor from avocado seed. Archives of Toxicology Supplement. 6:52-57.

Zhu Y., Kolar P., Shah S. B., Cheng J. J. \& Lim P. K. 2016. Avocado seed-derived activated carbon for mitigation of aqueous ammonium. Industrial Crops and Products. 92:34-41.

Zhu Y., Kolar P., Shah S. B., Cheng J. J. \& Lim P. K. 2018. Simultaneous mitigation of $p$-cresol and ammonium using activated carbon from avocado seed. Environmental Technology \& Innovation. 9:63-73. 
Zakariya U. A., Umar A. U., Sabiu M. D., \& Abdullahi S. 2016. Comparative hepatotoxic effects of aqueous and phenolic extracts of avocado (Persea americana) seed in Wistar albino rats. International Journal of Biochemistry Research \& Review. 10(4):1-6. 